\title{
The marketing of seasoned equity offerings
}

\author{
Xiaohui Gao* \\ University of Hong Kong \\ Jay R. Ritter \\ University of Florida
}

March 10, 2010

forthcoming, Journal of Financial Economics

JEL classification:

G14, G24, G32

Keywords:

Marketing of securities; Follow-on offerings; Seasoned equity offerings; Bookbuilding

* Corresponding author.

E-mail address: xiaohui@hku.hk (Xiaohui Gao).

We thank a very constructive referee (Robin Greenwood), Franklin Allen, David T. Brown, Jonathan Hamilton, Frank Hathaway, Kathleen Kahle, Jason Karceski, Jason Kliewer, M. Nimalendran, Michael Ryngaert, Donghang Zhang, and seminar participants at the Chinese University of Hong Kong, City University of Hong Kong, Erasmus University, the Helsinki School of Economics, KAIST, Norwegian School of Management (BI), Singapore Management University, the University of Florida, and the University of Hong Kong for helpful comments and suggestions. Xiaohui Gao gratefully acknowledge the research support from the Faculty of Business and Economics at the University of Hong Kong and the Research Grants Council of the Hong Kong SAR government. Special thanks to Xiaoding Liu for research assistance. 


\title{
The marketing of seasoned equity offerings
}

\begin{abstract}
In an accelerated seasoned equity offering (SEO), an issuer foregoes the investment bank's marketing efforts in return for a lower fee. To explain why many issuing firms choose a higher cost fully marketed offer, we posit that the marketing effort flattens the issuer's short-run demand curve. Alternatively stated, with a fully marketed offer, the issuer is paying investment bankers to create demand, making the elasticity of demand at the time of issuance an endogenous choice variable. Empirical analysis shows that both the pre-issue elasticity of the issuing firm's demand curve and the offer size are important determinants of the offer method choice. We find evidence of a large transitory increase in the elasticity of demand for issuers conducting fully marketed SEOs.
\end{abstract}




\section{Introduction}

Many of the services provided by investment bankers can be thought of as creating demand for securities. Sell-side research analysts and equity capital markets sales employees clearly perform this marketing function (Chung and Jo, 1996). In this paper, we focus on the underwriting of seasoned equity offerings (SEOs), also known as follow-on offerings, which can be categorized into three major types by their offer methods: fully marketed offers, accelerated offers, and rights offers. ${ }^{1}$ The academic literature on the issue method for SEOs has focused on rights versus fully marketed offers, although rights offers are virtually nonexistent in the U.S. ${ }^{2}$ In contrast, there is no theoretical or empirical treatment of the choice between accelerated offers, which include bought deals and accelerated bookbuilt SEOs, and fully marketed offers, also known as traditional bookbuilt offers.

Before the late 1990s, the U.S. equity market was dominated by fully marketed SEOs. In contrast, many Asian, Australian, and European SEOs used rights offers. In a rights offer, current shareholders are given short-term warrants to purchase newly issued shares on a pro rata basis at a fixed offer price. During the last decade, accelerated SEOs, especially accelerated bookbuilt offers, have become common. In 2004, more than half of the total global SEO proceeds were raised through accelerated SEOs, according to Table 2 in Bortolotti, Megginson, and Smart (2008)..$^{3}$

Fully marketed SEOs are issued in much the same way as bookbuilt initial public offerings (IPOs). Firms issue primary shares and current shareholders wishing to sell existing shares issue secondary shares. The issuer negotiates with one or more investment banks to market the offer and then sets the price. The lead underwriter or underwriters conduct a due diligence investigation and "certify" the quality of the company, and a prospectus is printed. As

\footnotetext{
${ }^{1}$ Throughout this paper, the terms fully marketed, fully underwritten, regular, firm commitment, traditional bookbuilt, bookbuilt, and conventional offers are used interchangeably unless noted otherwise.

${ }^{2}$ Previous studies on rights offers versus bookbuilt offers include Smith (1977), Eckbo and Masulis (1992), Bohren, Eckbo, and Michalsen (1997), and Rinne and Suominen (2008).

${ }^{3}$ Bortolotti, Megginson, and Smart's (2008) terminology of bought deals is slightly different from ours. They refer to bought deals in Canada as bought deals and bought deals in the US as block trades. We define US block trade offers as bought deals.
} 
part of the marketing effort to develop interest in the offer, a road show is conducted. In a typical road show, the issuer's management meets with selected institutional investors, analysts, and securities sales personnel over a two week period. At the same time, the bookrunner (which is always a lead underwriter) assesses investors' demand and builds an order book that is used to help determine the offer price. A syndicate of underwriters, led by the bookrunner, then distributes the shares, although for some of the underwriters, their only involvement may be in providing subsequent research coverage, or even less.

Accelerated offers include bought deals and accelerated bookbuilt offers. In the U.S., they are usually shelf registered offers. Bought deals started in the mid-1980s. With a bought deal, the issuing firm announces the amount of stock it wishes to sell and investment banks bid for these shares, usually by submitting bids shortly after the market's close. The bank that offers the highest net price wins the deal. The winning bank then resells the shares, primarily to institutional investors, usually within 24 hours. Because of this timing, bought deals are also known as overnight deals. Bought deals are essentially auctions to underwriters followed by open market sales.

Unlike bought deals, in accelerated bookbuilt offers, banks submit proposals, usually specifying a gross spread but not necessarily an offer price, for the right to underwrite the sale of the shares. The winning bank then usually forms a small underwriting syndicate and begins marketing the shares to institutional investors. The offer price is then negotiated between the issuing firm and the bank. The bookbuilding procedure is "accelerated" in the sense that no road show is conducted and the underwriting procedure is typically completed within 48 hours.

The major difference between a fully marketed offer and an accelerated offer, aside from the speed of completing the deal, is the extent of the underwriter's marketing of the issue. We use the differential marketing of seasoned equity offerings to explain the issuing firm's choice between a fully marketed offer and an accelerated offer. In our analysis, marketing flattens the demand curve of the issuer's stock. The underwriter's marketing effort, including a road show, can change the elasticity of demand for the issuing firm's stock, resulting in a higher offer price and stock price after the issue. This marketing effort does not come for free, however. The issuing firm needs to balance the gain from a higher stock price with the extra expenses associated with greater marketing effort. 
The bookbuilding literature has focused on the acquisition of information by underwriters about the state of demand, e.g., Benveniste and Spindt (1989) and Corwin and Schultz (2005). In contrast, we posit that an important feature of traditional bookbuilding is the creation of demand. While many studies have assumed that negatively sloped demand curves for stocks exist, these papers have taken the elasticity of demand as exogenous. In contrast, our analysis not only explicitly adopts a supply and demand framework to analyze SEOs, but posits that the demand curve that an issuing firm faces is affected by the choice of issue methods. In other words, the short-run demand curve that an issuing firm faces is an endogenous choice variable.

Marketing can change the short-run elasticity and achieve a higher offer price and postissue market price. The benefits of marketing are larger if the pre-issue demand curve is more inelastic or if the offer size is larger. Therefore, we predict that an issuer is more likely to pay the higher fees associated with a fully marketed offer, the more inelastic is its demand curve prior to the offer. The fully marketed offer method is also preferred if the offer size is large.

Our empirical results support these predictions. We use four measures to proxy for the demand elasticity. The first measure is an order flow inverse demand elasticity, the average daily ratio of the absolute value of returns to turnover. The second measure is an arbitrage risk measure, the variance of daily market model return residuals. The third measure is the stock's non-institutional ownership fraction. The fourth measure is the stock's average price impact using Trade and Quote (TAQ) data. We show that firms that face a relatively inelastic demand curve prior to the offer, raise a large amount of capital, or offer a large number of shares compared to the number of shares outstanding before the offer, are more likely to conduct a fully marketed SEO.

For an issuing firm that is average in other ways, if it has an above-average relative issue size of $30 \%$ of the pre-issue shares outstanding and ex ante has a relatively inelastic demand curve, with a value of the order flow inverse demand elasticity at the $90^{\text {th }}$ percentile, the probability of using an accelerated offer is only $1 \%$. On the other hand, if the issuer has a relative offer size of $10 \%$ and is at the $10^{\text {th }}$ percentile of the order flow inverse demand elasticity, the probability of using an accelerated offer is a sizeable $43 \%$. We also find that a smaller market capitalization and less analyst coverage all increase the probability of using a fully marketed offer. 
Consistent with our predictions, we find that issuers conducting fully marketed offers experience a large transitory increase in the short-run elasticity of demand in the month after the offering. Issuers using bought deals or accelerated bookbuilt offers experience transitory increases in their demand elasticities of $23 \%$ and $26 \%$, respectively, but fully marketed offers experience a $30 \%$ increase in the month after issuing relative to their post-issue values a few months later. When we control for the other determinants of the change in elasticities in a multiple regression, we confirm the univariate pattern that there is a larger transitory change in the elasticity for fully marketed deals than for accelerated deals.

Although the post-issue elasticity of demand is temporarily boosted for fully marketed offers, the offer price on average is set in a manner that does not take full advantage of this higher elasticity. The average fully marketed deal is underpriced by $3.4 \%$, whereas the average accelerated offer is underpriced by only $1.6 \%$.

Our framework is not mutually exclusive with the information asymmetry and information production frameworks adopted in other studies. Downward-sloping demand curves can arise from asymmetric information (Benveniste and Spindt, 1989), differences of opinion among investors (Hong and Stein, 2007; and Miller, 1977), a limited number of investors who are paying attention to the stock (Merton, 1987; Zhang, 2004; and Duffie, 2010), or a lack of close substitutes (Greenwood, 2005 and 2008; and Wurgler and Zhuravskaya, 2002). For all of the above reasons, a firm facing a relatively inelastic demand curve can benefit from fully marketing the offer.

Our study supports the argument that demand curve elasticity has a significant impact on corporate financial decisions. Two other papers reach the same conclusion. Hodrick (1999) studies tender offer choice in share repurchases and finds that firms that choose Dutch auctions instead of fixed-price tender offers tend to face more elastic demand curves. Baker, Coval, and Stein (2007) argue that for acquiring firms that face downward-sloping demand curves, investors' inertial behavior (i.e., the tendency to react passively) mitigates the negative merger announcement effect, and increases the benefit of a stock-for-stock merger relative to a cash acquisition. Our analysis is the first, however, to explicitly argue that the corporate financial decision may be intended to affect the elasticity. 


\section{The role of marketing in SEOs}

In a fully marketed SEO, the lead underwriters and the issuing firm's executives visit institutional investors to create interest in the offer. During this road show, institutional investors acquire information regarding the company. The road show process usually lasts for two weeks, so investors have plenty of time to investigate and make their investment decisions. In contrast, there is minimal marketing effort involved in an accelerated underwriting and investors have little time to evaluate the offer.

Our analysis of the role of marketing in SEOs assumes that there is a downward-sloping demand curve for the issuer's common stock, and that there is cross-sectional variation in the elasticity. There is widespread empirical evidence that both the short-run and long-run demand curves for stocks are negatively sloped. Studies of index additions and deletions universally find price effects, consistent with downward-sloping demand curves. Wurgler and Zhuravskaya (2002) show that stocks without close substitutes experience a larger price jump when added to the S\&P 500, implying less elastic short-run demand curves for these stocks. Greenwood (2005) studies the redefinition of the Nikkei 225 index in April 2000. He finds that not only do additions and deletions experience significant price changes, but securities that are not directly affected by the substitution of securities also experience abnormal returns due to their correlation with securities undergoing changes in demand.

Alternatively, one can model price effects as due to positively sloped supply curves rather than negatively sloped demand curves. Chacko, Jurek, and Stafford (2008) model transaction costs as fees that a market maker charges for immediate execution of limit orders. This results in an upward-sloping short-run supply curve being offered by the market maker. Their estimates of the short-run supply elasticity range from 4.0 to 7.3 when a stock experiences a $10 \%$ increase in demand.

Seasoned equity offerings result in an increase in the supply of shares to the public. In the U.S., the announcements are associated with stock price declines. After the SEO announcement, on average, the stock continues to experience a negative abnormal return until the offer (Corwin, 2003). The negative returns have been interpreted in the literature as due to a combination of information (Myers and Majluf, 1984) and price pressure caused by downward-sloping demand curves. Unlike index changes, the information effects associated with SEO announcements 
normally make estimating an elasticity problematic. Two studies of SEOs attempt to separate price pressure effects from information effects. Loderer, Cooney, and Van Drunen (1991) study the announcement effect of seasoned offerings by regulated firms. Their event study is a direct test on price elasticity of common stocks because regulated firms' equity issues are less likely to suffer from information effects. They estimate a median elasticity of -4.3 in their Table 4. Meidan (2005) uses instrumental variables to separate out information effects and finds support for the existence of temporary price pressure.

The effect of marketing on the price at which a firm can issue stock is illustrated in Fig. 1. Before the offer, the demand curve is represented by the solid line. The market equilibrium price is $P_{1}$, which is jointly determined by the aggregate demand and supply of shares. $P_{1}$ also represents the price that the stock will converge to in the long-run as the demand curve rotates from the steep short-run relation to a more elastic long-run relation. The offering represents an increase in supply (from $X_{1}$ to $X_{2}$ in Fig. 1). If there is no marketing, the short-run demand curve remains the same throughout the offering and as a result of the movement along the demand curve, the stock price drops from $P_{1}$ to $P_{2}$. If the issuing firm decides to market the offering, the marketing efforts will attract new investors and shift the demand curve out. To the degree that the information conveyed in the marketing effort results in more homogeneous opinions, the demand curve will be flatter as well.

In Fig. 1, the dashed line represents the new short-run demand curve when there is marketing, with the intersection of supply and demand now occurring at a higher offer price $P^{*}$. With the increase in the offer price from $P_{2}$ to $P^{*}$, the shaded rectangular area represents the issuer's gain in gross proceeds from marketing, calculated as the increase in the offer price multiplied by the number of shares issued. For a given supply increase, the gain from marketing will be larger the more inelastic is the pre-offer demand curve. If this gain is sufficiently large and exceeds the direct cost saving from the lower fees associated with using an accelerated offer, the issuing firm would prefer the fully marketed offer.

Also, note that the size of the shaded rectangle will be larger when there is a larger supply increase. A larger offer size represents a larger move along the short-run demand curve, which implies a larger price drop for any given negatively sloped demand curve. Consistent with this prediction, Mola and Loughran (2004, Table 6) and Intintoli and Kahle (2009, Table 4) report 
that the offer price discount, defined as the percentage price change from the previous market price to the offer price, increases with the relative issue size, although their studies do not distinguish between accelerated and fully marketed offers. In our analysis, a larger issue results in greater price pressure, causing a fully marketed offer to be preferred.

Empirical research shows both that marketing increases the number of investors who pay attention to a stock and that attention plays an important role in investors' trading behavior and stock prices. Busse and Green (2002) report that trading volume for Nasdaq-listed stocks increases by an average of 300,000 shares in the four minutes after an analyst has mentioned a stock favorably on CNBC's Midday Call segment. Barber and Odean (2008) test and confirm the hypothesis that individual investors are net buyers of attention-grabbing stocks, described as those that are in the news, have high trading volume, or have extreme one-day returns. In addition, Yuan (2008) finds that high attention also influences both the aggregate market price level and the trading behavior of institutional investors.

Two recent papers discuss the role of marketing with IPOs, although neither paper examines the demand curves for the shares directly. In the first paper, Cook, Kieschnick, and Van Ness (2006) posit that investment banks use pre-IPO marketing to attract retail investors, which benefits the issuers, the investment banks, and their regular (institutional) investors. The authors use pre-IPO media coverage as a proxy for pre-IPO marketing, but because of "quiet period" regulations in the US, it is not clear whether underwriters make any attempt to generate media coverage. Furthermore, Liu, Sherman, and Zhang (2008) report that financial journalists are more inclined to publish articles on IPOs that they expect to be "hot," suggesting that a severe reverse causality bias may be present in Cook et al.'s empirical work. In the second paper, Chahine, Ljungqvist, and Michaely (2008) examine the pre-IPO analyst reports for a sample of French IPOs. They conclude that the analyst reports are used to generate "hype" among retail investors, and this hype is associated with a higher offer price.

One other article focuses on the marketing of SEOs. Huang and Zhang (2010) posit that the use of multiple managing underwriters is motivated by marketing considerations. They report that if one additional managing underwriter is hired, the offer price discount is reduced by $0.26 \%$. They argue that the smaller price discount is a result of the additional managing underwriter's marketing efforts, which reduces the price pressure and the downside price risk. Consistent with 
their analysis, we find that fully marketed offers tend to have more co-managers and larger syndicate groups compared to accelerated offers. In our sample, the median accelerated SEO hires no co-manager. In contrast, the median fully marketed offer has two co-managers. Huang and Zhang focus on the gross spread and offer price discount to examine the impact of hiring additional managers on direct and indirect issue costs. Our study has a different focus. We examine the issuing firm's pre-issue demand elasticity and analyze the determinants of the offer method.

Given that the costs of conducting a road show are largely fixed costs, we predict that the benefits of a fully marketed offer exceed the costs if 1) the ex ante demand curve of the issuing firm's stock is relatively inelastic, and 2) the offer size is large. This cost-benefit analysis yields two testable hypotheses:

1. If the issuing firm's ex ante demand curve is more elastic, it is more likely to use an accelerated offer.

2. The smaller the offer size, the more likely it is that the issuer will use an accelerated offer.

We do not attempt to estimate the dollar value of the gain from marketing because it is difficult to find both the post-issue price with marketing, $P^{*}$, and the post-issue market price without marketing, $P_{2}$. To find the change between $P_{1}$ and $P^{*}$ is also a challenge. On the day of the SEO announcement, market efficiency suggests that the market price should immediately adjust to anticipate any price pressure effects associated with the supply increase on the issue day. At the same time, the market price should also immediately incorporate the information released by the announcement. Therefore, the observed price change on the announcement day is the combination of the information effect and the anticipated price pressure effect. To find $P^{*}$ requires isolating the information effect from the price pressure effect, which is difficult to implement empirically. Furthermore, the observed announcement-day closing price may still deviate from the expected post-issue price due to transaction costs and arbitrage limitations, as well as uncertainty about whether the deal will be completed.

\section{Sample and descriptive statistics}

\subsection{Sample selection}


We start with all US common stock seasoned equity offerings in the Dealogic Equity Capital Markets (ECM) Analytics Database between January 1, 1996 and December 31, 2007. To identify the offer method, we mainly rely on Dealogic's classification, supplemented by the length of time between the filing day and the trade day. In Appendix A, we compare the accuracy of Dealogic's classification with the Thomson Financial Securities Data Company's (SDC) new issues database classification of the offer method. We find that Dealogic's classifications are much more accurate.

We exclude American Depository Receipts (ADRs), best efforts and non-Securities and Exchange Commission (SEC)-registered offers, offers under SEC Rule 144A, private placements, rights offers, unit offers, closed-end funds, Real Estate Investment Trusts (REITs), and pure secondary offers. Pure secondary SEOs are offerings in which all of the shares are being sold by existing shareholders. We exclude pure secondary offerings because they are similar to large sales (block trades) in the open market. The issuer's stock must be listed on the New York Stock Exchange (NYSE), American Stock Exchange (Amex), or Nasdaq, and be present on the University of Chicago Center for Research in Security Prices (CRSP) database on the last trading day prior to the announcement day, the offer day, and the first trading day after the issue. We also exclude accelerated offers that are either identified as non-shelf offers or spend more than three calendar days from the filing to the offer. ${ }^{4}$

In addition to the other selection criteria, we require that an issuer has a pre-issue market capitalization of $\$ 75$ million. An issuer needs to file a shelf registration prior to conducting an accelerated SEO. ${ }^{5}$ In addition to meeting other requirements described in Bethel and Krigman

\footnotetext{
${ }^{4}$ Generally speaking, only companies that are eligible for shelf registrations are eligible for accelerated SEO offers. There are exceptions and possible data mistakes. For example, the offer by First Republic Bank on August 15, 2005, is exempted from registration under Section 3(a)(2) of the Securities Act of 1933. MBNA filed a shelf registration on March 29, 1999 and conducted a bought deal on August 14, 2000. But Dealogic reports this as a non-shelf takedown. Most of these deals are small offers with less than $\$ 100$ million in proceeds. We exclude all 35 non-shelf accelerated offers. Ten accelerated SEOs that spend more than three days from the filing to the offer are dropped. Inclusion of these ten deals has little impact on our results. Five of these ten are bought deals that spend more than 100 days from the filing to the offer. For example, Rowan Companies filed the registration on October 13, 1999 and completed the offer on February 16, 2000, so there are 126 calendar days between the filing and the offer.

${ }^{5}$ The shelf registration process allows issuing firms to file a single all-encompassing registration statement once every two years rather than filing individual registration statements for every security offering. Once its shelf registration statement is approved by the SEC, a firm can issue securities without further disclosure requirements or regulatory delays. In practice, even for bought and accelerated bookbuilt deals, firms normally issue a prospectus.
} 
(2008), a shelf registration requires the issuer to have at least $\$ 75$ million in market capitalization. This market capitalization requirement reduces our sample size from 3,614 to 3,276 SEOs.

Empirical studies treat shelf takedown and non-shelf takedown SEOs differently. Some studies exclude shelf registered offers (Altinkilic and Hansen, 2003; Huang and Zhang, 2010), and some restrict the sample to shelf registered offers only (Autore, Hutton, and Kovacs, 2008). We include both shelf and non-shelf offers, as does Corwin (2003).

\subsection{Offer methods}

Panel A of Table 1 reports the number of offers with each offer method and the total amount of proceeds raised in each year, categorized by offer method. The total proceeds include the exercised overallotment value. Unlike the SDC new issues database, Dealogic reliably reports the exercised amount. We adjust for inflation and report proceeds in dollars of 2007 purchasing power.

The number of SEOs fluctuates over the 12-year sample period, although the year-to-year fluctuation in volume is much smaller than for IPOs. The number of bought deals and accelerated bookbuilt offers increased substantially after 2000. In 1996, there was only one bought deal and there were no accelerated bookbuilt offers. In 2007, there were 27 bought deals and 46 accelerated bookbuilt offers. Bought deals and accelerated bookbuilt offers also have gained market share in terms of proceeds raised over time. In 2007, these accelerated offers account for $25 \%$ of the total proceeds raised in our sample SEOs.

Panel B of Table 1 compares shelf takedown and non-shelf takedown offers within each offer method. Over the 12-year sample period, there are 1,332 shelf takedown SEOs. Of those, 766 shelf takedown SEOs are fully marketed, 290 are bought deals, and 276 are accelerated bookbuilt offers. All of the 1,944 non-shelf takedown offers in our sample are fully marketed.

Shelf-registered issuers do not seem to have any dominating preference between accelerated offers and fully marketed offers. Almost $60 \%$ of the shelf takedown SEOs are fully marketed offers. Autore, Kumar, and Shome (2008) also conclude that neither method dominates among shelf-issuing firms. Therefore, we do not consider the issuer's endogenous decision on shelf registration as an explanatory variable in our empirical tests.

\section{3.. $\quad$ Offer characteristics}


Panel A of Table 2 shows six offer and firm characteristics categorized by the three offer methods. The first column reports the mean and median [in brackets] for the entire sample of SEOs, while the second, third, and fourth columns report the mean and median for, respectively, bought deals, accelerated bookbuilt SEOs, and fully marketed SEOs. The fifth column reports the mean and median difference between the accelerated offers (bought deals and accelerated bookbuilt offers combined) and the fully marketed offers. The last column reports the $p$-values from the Kruskal-Wallis (KW) test on the means and the Chi-squared test on the medians to test for a distribution difference between accelerated SEOs and fully marketed SEOs.

We adjust the pre-offer market capitalization and the offer proceeds for inflation. ${ }^{6}$ The average issuing firm in our sample has an adjusted (2007 purchasing power) market capitalization of $\$ 2.2$ billion before the offer. On average, the issuer is raising $\$ 206$ million in inflation-adjusted proceeds and has a relative offer size of $22.5 \%$, defined as the ratio of the offered shares to the shares outstanding prior to the issue. The average relative offer size is much larger than the average proceeds as a percentage of the average pre-issue market capitalization because small companies typically issue a much higher fraction of shares than large companies do. Primary shares, which are shares offered by the issuing firm, are on average $85 \%$ of the total number of shares offered, with most SEOs having $100 \%$ of the issue coming from the company rather than existing shareholders. Most of our sample offers, and almost all of our accelerated offers, have the entire issue composed of primary shares issued by the company. This is partly a manifestation of our exclusion of pure secondary offers. Bortolotti, Megginson, and Smart (2008) show that many accelerated offers are composed exclusively of secondary shares.

Table 2 shows that accelerated offers and fully marketed offers differ substantially from each other. Test statistics indicate that the difference between accelerated SEOs and fully marketed SEOs in most of the offer characteristics is statistically significant. Furthermore, frequently there is a monotonic relation in the means among the three groups, with accelerated bookbuilt offers in between. Accelerated bookbuilt SEOs tend to be chosen by larger firms and bought deals are chosen by the largest firms. Compared to an average issuer of a fully marketed offer, the average accelerated bookbuilt and bought deal issuer has a market cap three times as

\footnotetext{
${ }^{6}$ The market capitalization is calculated on the last trading day before the announcement of the offer. For firms with dual-class shares, the market cap is restricted to the share class being issued.
} 
big. The offer proceeds, however, show only modest differences across offer methods. As a result, the relative offer size for fully marketed deals is, on average, much larger.

In Fig. 2, we show a scatter diagram of the relation between the issuing firm's market capitalization prior to the offer and the relative offer size across offer methods for SEOs in 2007..$^{7}$ Among the 211 SEOs in $2007,91 \%$ of firms issuing more than $15 \%$ of their equity (72 out of 79) use fully marketed offers, whereas only $27 \%$ of firms issuing less than $10 \%$ (13 out of 49) do so. Fig. 2 shows that firms choosing fully marketed offers tend to be small firms selling a relatively large amount of shares. The larger relative offer size for fully marketed offers is consistent with our prediction: Firms that may suffer from a larger price decline due to a larger move along the pre-issue demand curve prefer to fully market the offer because the marketing effort flattens the demand curve and helps to achieve a higher offer price. Since small firms tend to have less elastic demand curves and thus receive greater benefits from marketing, it is not surprising to see that most small firms use fully marketed offers.

The last two rows in Panel A of Table 2 examine the number of analysts who are following the issuer's stock and the stock's average bid-ask spread. An analyst is included if he or she posts at least one recommendation within 12 months prior to the offer. The analyst recommendations are obtained from the Institutional Brokers' Estimate System (IBES) database (early 2008 download). During the year before each SEO, the average number of analysts that follow an SEO is five, which is comparable to the number reported in Huang and Zhang (2010) for SEOs from 1995 - 2004. Accelerated issuers, which tend to be larger companies, receive significantly more analyst coverage, with an average of 7-9 analysts following the stock while fully marketed issuers only have four analysts on average. If an issuing firm receives little analyst coverage prior to the offer, it may decide to do a road show to reach more investors and promote the stock. The issuer may also be willing to pay a higher gross spread as a way of compensating additional managing underwriters for initiation of research coverage.

The bid-ask spread is the average daily bid-ask spread, scaled by the closing stock price on that day, over the 250 trading days prior to the announcement of the SEO. Accelerated issuers tend to have a smaller proportional bid-ask spread, an average of $0.64 \%$, compared to fully

\footnotetext{
${ }^{7}$ Other years show the same pattern. Only one year's data are used to avoid obscuring the pattern by plotting too many points.
} 
marketed offers with an average of $1.64 \%$. However, the bid-ask spread exhibits a sharp declining trend in the sample period, from an average of $2.69 \%$ in 1996 to an average of $0.31 \%$ in 2007. This coincides with the increase in accelerated SEOs during our sample period and may lead to spurious results between the bid-ask spread and the SEO method selection. Therefore, we detrend the bid-ask spread in our multivariate regressions in Section 4.

The univariate results show that accelerated SEOs tend to be conducted by large firms, and the relative offer sizes are smaller than for fully marketed offers. In unreported results, using our sample of accelerated offers, we run a logistic regression with the dependent variable being zero for bought deals and one for accelerated bookbuilt offers. The regression has no reliable explanatory power to predict which of these accelerated methods is used. Thus, in the rest of our empirical analysis, we group bought deals and accelerated bookbuilt offers together, and compare these accelerated offers with fully marketed offers.

\section{Price elasticity proxies and determinants of offer method}

In this section, we examine proxies for the issuer's pre-offer demand elasticity and conduct a multivariate analysis of the offer method choice.

\subsection{Price elasticity proxy estimation}

The definition of elasticity of demand is the proportional change in quantity demanded

for a proportional change in price, $\frac{(\Delta q / q)}{(\Delta p / p)}$. In general, we cannot precisely construct the demand and supply schedules for individual stocks and directly measure the price elasticity. Due to data limitations that prevent us from identifying supply shifts along a given demand curve or vice versa, we adopt four measures to proxy for the elasticity of demand for the issuing firm's stock.

The first measure of price elasticity is an average daily order flow inverse price elasticity measure, $A_{1}$. The daily order flow inverse price elasticity on day $t$ is defined as the ratio between the absolute value of the stock's raw return and its turnover, with turnover defined as the trading volume divided by the number of shares outstanding. If the stock is listed on Nasdaq, we apply various adjustments to the trading volume and Appendix B explains our adjustments in detail. This ratio is called an inverse elasticity because for an elasticity, quantity is in the numerator 
rather than the denominator. (The stock return is in the numerator to avoid zeroes in the denominator.) $A_{1}$ is the average daily inverse elasticity over the 250 trading-day window, [-250,1], prior to the announcement date: ${ }^{8}$

$$
A_{1}=\frac{1}{250} \sum_{t=1}^{250}\left(\frac{\mid \text { Stock Raw Return }_{t} \mid}{{\text { Number of Shares Traded } t / \text { Number of Shares Outstanding }_{t}}_{\text {Number }}}\right) .
$$

If a stock has a $-2 \%$ return on a day when $0.5 \%$ of its shares outstanding are traded, it would have an inverse elasticity of 4.0 on that day.

$A_{1}$ is not a precise measure of an individual stock's demand elasticity because the trading volume includes both buyer-initiated and seller-initiated trades. However, Kalay, Sade, and Wohl's (2004) study on all orders that are placed at the Tel Aviv Stock Exchange (TASE) empirically shows a positive relationship between the flow demand for the stock and its daily turnover. Therefore, using the total volume instead of just buyer-initiated volume in the denominator of $A_{1}$ still produces a proxy for the demand elasticity. A large $A_{1}$ reflects a large change in price if there is a demand or supply shock, which implies an inelastic demand curve. $A_{1}$ can also be thought of as a measure of the lack of depth for a stock.

The second measure of price elasticity is an arbitrage risk measure, $A_{2}$, as used in Wurgler and Zhuravskaya (2002). ${ }^{9} A_{2}$ is the variance of the market model OLS regression residuals estimated over the 250 trading days prior to the announcement date:

$$
\left(R_{i, t}-R_{f t}\right)=\alpha+\beta \times\left(R_{M, t}-R_{f t}\right)+\varepsilon_{t} \quad t=1,2, \ldots, 250 .
$$

In Wurgler and Zhuravskaya's (2002) model, the demand elasticity for a stock is determined by the arbitrage risk. Arbitrageurs keep the demand curve flat if the asset has perfect substitutes and the arbitrage risk is zero. On the other hand, if the asset does not have perfect

${ }^{8}$ If the company is listed on CRSP for less than 250 trading days prior to the SEO, we start with the first date available on CRSP. For the 15 fully marketed offers for which there are more than 180 calendar days from the announcement to the offer, we estimate $A_{1}$ and $A_{2}$ over the 250 trading days ending 180 calendar days prior to the offer so that the estimation window is not too distant from the offer date. This treatment has no impact on our results.

${ }^{9}$ Wurgler and Zhuravskaya (2002) use two arbitrage risk measures. The other arbitrage risk measure is the residual variance of a zero-net-investment portfolio with three substitute stocks. The three stocks are matched on industry and as closely as possible on market capitalization and book-to-market ratio. The two measures are highly correlated (0.97) and all our results remain qualitatively unchanged with the other arbitrage risk measure. 
substitutes, the demand curve is downward sloping because the arbitrage risk is nonzero and arbitrageurs are risk averse. The larger the arbitrage risk, $A_{2}$, the more inelastic the demand curve is. Their empirical analysis shows a positive relation between arbitrage risk and returns on the announcement day of S\&P 500 additions, which suggests that stocks with greater arbitrage risk have less elastic demand.

Our third measure of price elasticity is the stock's non-institutional ownership, $A_{3}$, measured as $100 \% \times(1-$ institutional ownership $)$. The institutional ownership fraction, the ratio of long institutional positions divided by shares outstanding, is constructed from Thomson Reuters' CDA/Spectrum Institutional (13f) Holdings database at the end of the latest quarter prior to the SEO offer date. Some firms have more than $100 \%$ institutional ownership due to outstanding convertible debt and convertible bond arbitrage. Convertible bond arbitrage typically involves shorting the stock, which increases the gross number of shares available to more than $100 \%$ of the shares outstanding. Table 1 of Asquith, Pathak, and Ritter (2005) lists 14 stocks in December 2002 with institutional ownership of more than 100\%. At the other extreme, some recent IPOs have very low institutional ownership because a large proportion of shares are held by insiders during the lock-up period. To reduce the influence of outliers, we winsorize institutional ownership at $10 \%$ and $100 \%$.

If a stock's institutional ownership is high, its demand curve should be more elastic for two reasons. First, more of its shares are available for lending so short-sales constraints bind less tightly. Second, institutional investors tend to follow individual stocks more closely than retail investors do (Baker, Coval, and Stein, 2007). If there is a big change in the stock's demand or supply, institutional investors will absorb the demand or supply shocks quickly. Higher values of $A_{3}$, representing lower institutional ownership, are associated with less elastic demand.

The fourth measure of price elasticity is a high-frequency measure, the stock's average price impact, calculated over the 15 trading days $[-15,-1]$ prior to the SEO announcement using TAQ data. We follow Barkley, Naranjo, and Nimalendran (2008) and define price impact as the change in the midpoint of the bid and ask quotes over a five-minute interval after a transaction. For a transaction executed at time $t$, let $Q_{\text {mid-point, } t}$ be the midpoint of the bid and ask quotes, which are the nearest quotes that precede the transaction by at least five seconds. Let $Q_{\text {mid-point } t+5 \text { minutes }}$ be 
the midpoint of the matched bid and ask quotes after five minutes. The price impact, $I_{t}$, for this transaction is defined as $I_{t}=\frac{\text { Absolute Value of }\left(\ln \left(Q_{\text {mid-point }, t+5 \text { minutes }}\right)-\ln \left(Q_{\text {mid-point }, t}\right)\right)}{\text { Number of Shares in the Transaction }}$, with the number of shares measured in hundred thousands. The daily price impact is the average price impact of all transactions on day $n, I_{n}=\frac{1}{T} \sum_{t=1}^{\mathrm{T}} I_{n, t}$, and the median value of $I_{\mathrm{n}}$ over the 15 trading days prior to the SEO announcement is our fourth proxy for demand elasticity, $A_{4}$. This highfrequency price impact measure shows a strong increasing trend during our sample period due to the decline in market depth that accompanied the decline in bid-ask spreads, and this coincides with the increase in accelerated SEOs at the same time. Therefore, we detrend $A_{4}$ by subtracting the yearly sample average price impact. $A_{4}$ measures the price change due to a given transaction, and is larger the more inelastic the demand curve is.

The order flow inverse demand elasticity, the arbitrage risk measure, non-institutional ownership, and the average price impact measure are all proxies for the individual stock's demand elasticity. All four measures are negatively related to the issuing firm's stock demand elasticity prior to the offer, with a high value indicating inelastic demand.

To reduce the influence of extreme values, we use a natural log transformation of $A_{1}$ and $A_{2} .{ }^{10}$ With $A_{3}$, we apply the log transformation to the winsorized non-institutional ownership. The natural logarithm of zero non-institutional ownership is set equal to zero. For $A_{4}$, we add a constant of 100 to avoid negative values before applying a log transformation.

Panel $\mathrm{B}$ in Table 2 reports the means and median of the adjusted $A_{1}, A_{2}, A_{3}$, and $A_{4}$ values, and of their logged values. As expected, the log transformations significantly reduce the right skewness. Our estimates of $A_{2}$ are comparable to what Wurgler and Zhuravskaya (2002) report, and our estimates of $A_{4}$ are comparable to those in Barkley, Naranjo, and Nimalendran (2008). On average, fully marketed SEOs have inverse elasticity and arbitrage risk approximately twice as high as for bought deals and accelerated bookbuilt offers. Comparing columns 2 and 3 with

\footnotetext{
${ }^{10}$ The order flow inverse demand elasticity, $A_{1}$, has a highly skewed distribution, ranging from 0.03 to 1,000 . For $A_{1}$, roughly $1 \%$ of the sample takes an extreme value because the annualized turnover of the stock is less than 5\%. For example, Centennial Communications Corp.'s average daily turnover in the year prior to its November 2003 SEO was $0.02 \%$, corresponding to an annual turnover of $5 \%$. This small turnover rate generates an $A_{1}$ of 840 , almost 100 times the unconditional median of 9.02 .
} 
column 4, we find the same pattern for all four measures, although the pattern for $A_{4}$ is weak. This shows that fully marketed offers are dominated by issuers with relatively inelastic preannouncement demand curves. The univariate results are consistent with our prediction that if the demand curve is more inelastic, the issuing firm is more likely to choose a fully marketed offer.

In unreported results, we perform several robustness checks. We substitute the stock's raw return in $A_{1}$ by its market-adjusted return. The patterns remain qualitatively the same. Our results are also robust to the specification of the time window. We estimate $A_{1}$ and $A_{2}$ over onemonth, three-month, and six-month windows prior to the announcement date and all estimates are qualitatively similar across the different windows.

\subsection{Determinants of the offer method}

Next, we examine the determinants of the choice of offer method in a multivariate framework.

\subsubsection{Logistic regression results}

Our univariate analysis shows that the choice of offer method is related to firm and offer characteristics. In the multivariate analysis, we include ten firm and offer characteristic variables as explanatory variables. The first four variables are our proxies for the elasticity of the short-run demand curve: the inverse elasticity, the arbitrage risk, the non-institutional ownership, and the price impact. They are moderately correlated $(0.23,0.37,0.20$, and 0.13$)$ with each other. The next three firm characteristics are the issuing firm's inflation-adjusted market capitalization prior to the announcement; the average bid-ask spread, scaled by the stock price, over the 250 trading days prior to the announcement; and the number of analysts covering the issuer in the 12 months before the offer, obtained from the IBES database. We apply natural log transformations on these variables, all of which have right-skewed distributions. To control for the strong declining trend in the bid-ask spread, we detrend the log transformed bid-ask spread by subtracting the mean value of this variable from SEOs in the same calendar year,

Detrended Ln $\left(\frac{\text { bid-ask spread }}{\text { price }}\right)=\operatorname{Ln}\left(\frac{\text { bid-ask spread }}{\text { price }}\right)$ - year $t$ average logged value. The three 
offer characteristic variables are the logarithm of the inflation-adjusted offer proceeds, the relative offer size, and the fraction of the offer that is primary shares. ${ }^{11}$

We use a binomial logistic model to investigate the determinants of the offer method. The dependent variable is a dichotomous variable for which accelerated offers, including bought deals and accelerated bookbuilt offers, equal one, and fully marketed offers equal zero. The binomial logistic model is estimated as follows:

$$
\begin{aligned}
& \operatorname{Pr}(\text { Method }=\text { Accelerated Deal })=\frac{1}{1+e^{-u}}, \\
& \text { where } \begin{aligned}
u=\gamma_{0} & +\gamma_{1} \operatorname{Ln}\left(A_{1}\right)+\gamma_{2} \operatorname{Ln}\left(A_{2}\right)+\gamma_{3} \operatorname{Ln}\left(A_{3}\right)+\gamma_{4} \operatorname{Ln}\left(A_{4}\right)+\gamma_{5} \operatorname{Ln}(\text { Market Cap }) \\
& +\gamma_{6} \operatorname{Ln}(\text { Proceeds })+\gamma_{7} \text { RelativeSize }+\gamma_{8} \text { PrimaryFraction } \\
& +\gamma_{9} \operatorname{Ln}(1+\text { Number of Analysts })+\gamma_{10} \text { Detrended } \operatorname{Ln}(\text { Bid-ask Spread })+\mathcal{E}
\end{aligned}
\end{aligned}
$$

Table 3 presents the binomial logistic regression results. As predicted, the coefficients on the first three demand elasticity measures are reliably negative. Larger order flow inverse elasticity $\left(\operatorname{Ln}\left(A_{1}\right)\right)$, higher arbitrage risk $\left(\operatorname{Ln}\left(A_{2}\right)\right)$, or higher non-institutional ownership $\left(\operatorname{Ln}\left(A_{3}\right)\right)$ indicates a more inelastic demand curve, and the negative coefficients imply that this inelasticity encourages issuers to choose a fully marketed offer instead of an accelerated offer. The price impact measure $\left(\operatorname{Ln}\left(A_{4}\right)\right)$ has an unexpected positive impact but the impact is very small and insignificant. The results are very similar if we include only one of $\operatorname{Ln}\left(A_{1}\right), \operatorname{Ln}\left(A_{2}\right)$, and $\operatorname{Ln}\left(A_{3}\right)$ rather than all four in the logistic regression, or if we interact each elasticity proxy with the relative offer size.

In unreported results, we also include interaction terms. An interaction term of a demand elasticity proxy and the relative offer size is motivated as a measure of the potential area of the shaded rectangle in Fig. 1. The larger the product of the two terms is, the more benefit marketing can achieve. Consistent with our hypothesis, if we include one interaction

\footnotetext{
${ }^{11}$ The four elasticity proxies are strongly correlated with the log of the issuing firm's market capitalization, the detrended bid-ask spread, and the number of analysts, indicating that small firms and firms with relatively high information asymmetry have relatively inelastic demand curves. The relative offer size is highly negatively correlated (-0.62) with firm size because of the tendency of large firms to not raise enormous amounts of money. Although the market capitalization and the proceeds are highly correlated with each other, our results are qualitatively unchanged if we drop either the market capitalization or the proceeds. We include $\ln (\mathrm{MV})$, $\ln$ (Proceeds), and the relative offer size as explanatory variables. Relative offer size is approximately proceeds/market value, but since we don't use its logarithm $(\ln ($ Proceeds $/ M V)=\ln ($ Proceeds $)-\ln (M V))$, there is not a multicolinearity problem.
} 
term, or four at the same time, the coefficient before the interactive term is generally significantly negative, implying that issuers are more likely to use a fully marketed offer the more the gross proceeds would be boosted. The coefficients before the rest of the variables remain qualitatively unchanged.

Both the inflation-adjusted proceeds and the relative offer size have a significantly negative impact on the probability of an accelerated offer. This indicates that if the issuer is raising a large amount of capital or is increasing the number of shares outstanding by a large fraction, a fully marketed offer is more likely, as predicted. The model correctly predicts almost $90 \%$ of the sample offer method, although it should be noted that $83 \%$ of the offers are fully marketed.

The logistic model applies a logistic transformation to the probability of an accelerated offer, making the coefficient estimates hard to interpret. In Table 3, we report two marginal effects to better illustrate the magnitude of each explanatory variable's contribution to the probability of choosing an accelerated offer. The first marginal effect is calculated at the sample medians. Take $\operatorname{Ln}\left(A_{1}\right)$, for example. Holding the rest of the explanatory variables at their sample median levels, we calculate the two probabilities of an accelerated offer when $\operatorname{Ln}\left(A_{1}\right)$ is \pm 0.5 standard deviations higher than its median. The difference between the two probabilities is the marginal effect for $\operatorname{Ln}\left(A_{1}\right)$ at the medians, which represents the change in the probability of an accelerated offer given a one-standard deviation change in $\operatorname{Ln}\left(A_{1}\right)$. The rest of the marginal effects at the medians are calculated in a similar way. Table 3 shows that a one-standard deviation increase in $\operatorname{Ln}\left(A_{1}\right), \operatorname{Ln}\left(A_{2}\right)$, or $\operatorname{Ln}\left(A_{3}\right)$ decreases the probability of an accelerated offer by $10.0 \%, 2.05 \%$, and $1.4 \%$, respectively.

The marginal effects at the medians are modest, reflecting the fact that the median firm in our sample has a high probability of using a fully marketed offer. The unconditional probability is $83 \%$, suggesting that the median firm has a high probability of using a fully marketed offer whether or not one of the variables is within one-half standard deviation of its median value. If we evaluate the marginal effects for a similar change in a variable when the values of this and other variables are in a region for which there are greater sensitivities, the marginal effects are much stronger, reflecting the nonlinear nature of the logit specification in Eq. (1). Therefore, we also report the marginal effects at the $25^{\text {th }}$ or $75^{\text {th }}$ percentile, depending on whether a variable has 
a negative or positive coefficient in Table 3. We hold $\operatorname{Ln}\left(A_{1}\right), \operatorname{Ln}\left(A_{2}\right), \operatorname{Ln}\left(A_{3}\right)$, the offer proceeds, and the relative size at their $25^{\text {th }}$ percentiles, and $\operatorname{Ln}\left(A_{4}\right)$, the market capitalization, the primary fraction, the bid-ask spread, and the number of analysts at their $75^{\text {th }}$ percentiles. The resulting marginal effects are stronger than those at the medians.

The following example illustrates the marginal effects at the $25^{\text {th }}$ or $75^{\text {th }}$ percentile. We start with a firm at the bottom $25^{\text {th }}$ percentile of the order flow inverse demand elasticity, which has a value of $\operatorname{Ln}\left(A_{1}\right)$ equal to 1.28 . This firm has a more elastic demand curve than all but $25 \%$ of the sample. We hold the residual variance $\operatorname{Ln}\left(A_{2}\right)$, non-institutional ownership $\operatorname{Ln}\left(A_{3}\right)$, the offer proceeds, and the relative size at the $25^{\text {th }}$ percentile, and the price impact $\operatorname{Ln}\left(A_{4}\right)$, the market capitalization, the primary fraction, the bid-ask spread, and the number of analysts at the $75^{\text {th }}$ percentile. If we increase $\operatorname{Ln}\left(A_{1}\right)$ from one-half standard deviation below to one-half standard deviation above the $25^{\text {th }}$ percentile, the probability of an accelerated offer decreases from $80 \%$ to $59.5 \%$, a marginal effect of $20.5 \%$. Similarly, moving from one-half standard deviation below to one-half standard deviation above the $25^{\text {th }}$ percentile of $\operatorname{Ln}\left(A_{2}\right)$ decreases the probability of an accelerated offer from $72.9 \%$ to $68.6 \%$, a marginal effect of $4.3 \%$. For these values of the explanatory variables, both the offer proceeds and the relative offer size have a large impact on the offer method choice: a one-standard deviation increase in the log offer proceeds or relative offer size decreases the probability of an accelerated offer from $80.0 \%$ to $59.7 \%$ or from $84.1 \%$ to $52.7 \%$, respectively.

The multivariate regression results support our first and second hypotheses. Both the preissue demand elasticity and the offer size, measured as either the absolute size or the relative size, are important determinants of the offer method. Firms facing a more inelastic demand curve are more likely to fully market the offer, as are issuers selling a large number of shares, either in absolute terms or relative to the number of shares outstanding prior to the offer.

The results in Table 3 reveal other important determinants of the offer method. A larger firm size increases the probability of an accelerated offer, consistent with the pattern in Fig. 2. More analysts covering the stock increases the probability of an accelerated offer. Both market capitalization and analyst coverage can be viewed as proxies for information asymmetry and the elasticity of demand. Table 3 also shows that a larger fraction of primary shares increases the probability of using an accelerated offer. This last finding is probably a consequence of 
excluding pure secondary offers from our sample, since accelerated offers tend to be either pure primary or pure secondary offers. Lastly, the detrended log bid-ask spread is positively related to the likelihood of an accelerated offer. This is a surprising result, since we would expect that stocks with a high bid-ask spread would be more likely to use a fully marketed offer. It should be noted, however, that in an unreported univariate regression, the detrended bid-ask spread has the expected negative sign but is not significant.

\subsubsection{Endogeneity issues}

One potential concern is that the offer size is determined jointly with the choice of the offer method, rather than the offer size being predetermined. For a fully marketed offer, if the stock price drops too much after the announcement, or there is little demand for the issue, the issuing firm may reduce the offer size or cancel the offer. Similarly, the issuer sometimes increases the offer size if the demand is strong. For an accelerated bookbuilt offer, the underwriter has little time to assess investors' demand but may still increase or decrease the offer size in consultation with the issuer. We compare the offer proceeds initially stated in the preliminary prospectus and the actual offer size. Between $31 \%$ and $34 \%$ of firms using each of these two offer methods reduce the number of shares offered.

For our empirical analysis, the question is whether this potential endogeneity problem biases our results. To examine this, we replace the actual offer size with the initial offer size in the regression. The relative offer size is redefined as the ratio between the initial deal size, announced at the filing, and the issuing firm's pre-announcement market capitalization. Our results remain virtually identical, so this potential endogeneity problem does not affect our conclusions.

\subsubsection{Robustness}

During our 12-year sample period, 1,573 firms conduct only one follow-on offering and 660 firms conduct more than one SEO. Among the multiple issuers, the average time between two issues is 34 months. Among the 660 repeat issuers, 24 conduct more than five offers, with the most frequent issuers being financial firms. Two firms, Allied Capital and American Capital Strategies, which invest in buyouts, each did more than ten offers. We identify 265 SEOs for which the offer method is different from the most recent SEO by the same issuer. Among the 58 SEOs that switched from an accelerated offer to a fully marketed offer, 48 have a larger relative 
offer size compared to the previous accelerated offer. Among the 207 SEOs that switched from a fully marketed offer to an accelerated offer, 172 have a smaller relative offer size. These results suggest that issuers are consciously choosing among the offer methods rather than just following a time trend.

In each of the first five years of our 1996 - 2007 sample period, as shown in Table 1, less than $10 \%$ of SEOs use an accelerated offer, whereas in each of the last seven years, at least $20 \%$ of SEOs do so. Thus, we rerun the binomial regression for the subperiod 2001 to 2007 and the results are qualitatively the same. The results are generally stronger in this subperiod, with the exception being that the counterintuitive positive coefficient on the bid-ask spread becomes insignificant.

\subsubsection{Does speed rather than marketing determine the issue method?}

An alternative explanation for the choice of an accelerated offer is that the issuing firm has a preference for speed in the raising of equity capital. In unreported results, we conduct a binomial logit regression analogous to that in Table 3, but with two proxies for the demand for speed added: the pre-issue stock price runup and the variance of the stock's returns. Neither of these proxies has the correct sign to support the hypothesis that accelerated offers are motivated by a desire for speed in raising equity capital.

It is worth noting that during our sample period, there is a monotonic downtrend in the median time between the announcement and completion of fully marketed deals. In 1996, the median time is 31 days, decreasing to only seven days in 2007 . Therefore, the speed advantage of an accelerated deal may have become less important in recent years.

\subsection{Post-issue demand elasticity}

In our analysis, the underwriter's marketing efforts flatten the issuer's demand curve in the short run. We expect this effect to be transitory. Logically, we would not expect that the elasticity of demand for a stock today would depend on what issue method was used for an SEO that occurred five years ago. How short the short run is, however, is an empirical question.

Because SEOs usually occur after large stock price run-ups, resulting in increased analyst coverage, and the issue itself increases the market value, we would expect to see an increase in the elasticity of demand for all offer methods when measured relative to the average value over the previous year. Furthermore, the attention associated with the issue is likely to increase the 
elasticity in the short run, irrespective of the offer method used. Also, if a firm waited to conduct its SEO until asymmetric information had declined, we would observe an increase in elasticity due to this timing. If marketing affects the elasticity, however, we expect that the short-run increase would be greatest for fully marketed SEOs.

To test the prediction that there is an increase in the short-run demand elasticity and the increase is bigger for fully marketed offers, we focus on the change in $\operatorname{Ln}\left(A_{1}\right)$ because this measure appears to be the best proxy for the elasticity of demand, as measured by both the statistical significance and the marginal effects in Table 3.

In Table 4, Panel A, we report the pre- and post-issue average values of $\operatorname{Ln}\left(A_{1}\right)$ for the three offer methods. The issue day is day 0 . The pre-issue window is the 250 trading days prior to the offer, $[-250,-1]$, and the five consecutive post-issue trading-day windows are $[+1,+21]$, $[+22,+42],[+43,+64],[+65,+125]$, and $[+126,+250]$. Fig. 3 graphs these pre- and post-issue values. Both accelerated and fully marketed SEOs experience an economically significant decrease in $\operatorname{Ln}\left(A_{1}\right)$ from the pre-issue average, which indicates that the demand curve becomes more elastic after the issue irrespective of the offer method. In the month after the issue, $\operatorname{Ln}\left(A_{1}\right)$ declines by an average of $48 \%$ (from 2.18 to 1.14) from its pre-issue value.

$\operatorname{Ln}\left(A_{1}\right)$ quickly rebounds, however, approaching its $[+126,+250]$ value within three months for all three deal types. For bought deals, accelerated bookbuilt offers, and fully marketed offers, Panel B of Table 4 shows that the $[+64,+125]$ values are economically and statistically indistinguishable from the $[+126,+250]$ values for $\operatorname{Ln}\left(A_{1}\right)$. Because the patterns indicate that the post-issue value of $\operatorname{Ln}\left(A_{1}\right)$ stabilizes in just a matter of months, we use the $[+126,+250]$ value of $\operatorname{Ln}\left(A_{1}\right)$ as the stabilized post-issue $\operatorname{Ln}\left(A_{1}\right)$.

The difference between the mean $\operatorname{Ln}\left(A_{1}\right)$ in $[+126,+250]$ and $[+1,+21]$ is 0.23 for bought deals and 0.27 for accelerated bookbuilt deals, but a much larger 0.53 for fully marketed offers. In percentage terms, relative to their $[+126,+250]$ values, the $[+1,+21]$ numbers are, respectively, $23 \%, 26 \%$, and $30 \%$ lower. This pattern supports our prediction that the marketing effort associated with fully marketed offers results in a larger temporary increase in the elasticity of demand than if there is little or no marketing effort.

This larger change for fully marketed deals may be partly attributable to the larger relative offer sizes and larger pre-issue stock price run-ups for the companies choosing fully 
marketed deals. Because the univariate patterns in Panels A and B do not control for these patterns, in Panel C we report multiple regression results for the changes in $\operatorname{Ln}\left(A_{1}\right)$.

Specifically, we examine the change in $\operatorname{Ln}\left(A_{1}\right)$ with the following OLS regression: $\operatorname{Ln}\left(A_{1}\right)_{\text {window } 1}-\operatorname{Ln}\left(A_{1}\right)_{\text {window } 2}=\alpha+\beta_{1}$ Fully Marketed Dummy $\beta_{2} \operatorname{Ln}($ Pre-offer Stock Return $)$ $+\beta_{3} \operatorname{Ln}(\mathrm{MV})+\beta_{4} \operatorname{Ln}($ Proceeds $)+\beta_{5}$ Relative Size $+\beta_{6}$ Primary Fraction $+\beta_{7}\left(\operatorname{Ln}(1+\text { Analysts })_{[-125,-1]}-\operatorname{Ln}(1+\text { Analysts })_{[-250,-126]}\right)$ $+\beta_{8}\left(\operatorname{Ln}(\text { Bid-ask Spread })_{[-125,-1]}-\operatorname{Ln}(\text { Bid-ask Spread })_{[-250,-126]}\right)+\varepsilon$

The two dependent variables are $\operatorname{Ln}\left(A_{1}\right)_{[+126,+250]}-\operatorname{Ln}\left(A_{1}\right)_{[+1,+21]}$ and $\operatorname{Ln}\left(A_{1}\right)_{[+126,+250]}-\operatorname{Ln}\left(A_{1}\right)_{[-250,-1]}$. Because $A_{1}$ is the inverse elasticity, a positive value for the difference represents a higher (absolute value of the) elasticity of demand in the second of the two windows. The fully marketed dummy variable equals one if the SEO is a fully marketed offer and equals zero if it is an accelerated offer. Since the dependent variable is the change in $\operatorname{Ln}\left(A_{1}\right)$, we include as explanatory variables the increase in the number of analysts and the increase in the issuer's bid-ask spread. We do not include the change between the pre-issue and post-issue bid-ask spread or the change between the pre-issue and post-issue number of analysts because these changes should be affected by marketing. Marketing can attract more investors, increase the stock liquidity, and increase investors' demand for analyst coverage. Instead, we use the increase from days $[-250,-126]$ to $[-125,-1]$ as an instrument for the increase from the earlier window to $[+126,+250] .{ }^{12}$

Panel C of Table 4 reports the OLS regression results. In the first column, the dependent variable is $\operatorname{Ln}\left(A_{1}\right)_{[+126,+250]}-\operatorname{Ln}\left(A_{1}\right)_{[+1,+21]}$. The coefficient on the fully marketed dummy is a statistically significant 0.11 , showing that fully marketed offers experience a larger decrease in demand elasticity from the immediate post-issue period, $[+1,+21]$, to the post-issue stabilized period, $[+126,+250]$, than do accelerated offers. In other words, consistent with our prediction,

\footnotetext{
${ }^{12}$ We lose 269 observations for computing the average bid-ask spread on trading days [-250,-126] prior to the announcement because we exclude SEOs whose bid-ask spread data are not available in the CRSP files. Since, especially in the early years of our sample, most SEOs were announced approximately two months before the offer date, very few SEOs that occurred within eight months of the IPO date are included in the regressions. We also lose ten more SEOs because they were delisted prior to the beginning of the $6^{\text {th }}$ month after the offer.
} 
marketing effort results in a larger, but temporary, increase in demand elasticity. In the second column, the effect of a fully marketed offer on $\operatorname{Ln}\left(A_{1}\right)_{[+126,+250]}-\operatorname{Ln}\left(A_{1}\right)_{[-250,-1]}$ is negative but only marginally significant ( $t$-statistic of -1.50), indicating that fully marketed offers experience a slightly larger increase in post-issue demand elasticity relative to the pre-issue level than do accelerated offers. Combined, the regression results confirm that marketing at the time of the SEO significantly flattens the short-run demand curve but has minimal impact on the elasticity of demand once this elasticity has stabilized after a few months.

There are other factors that affect the change in $\operatorname{Ln}\left(A_{1}\right)$. To save space, we focus on the change from the pre-issue level to the stabilized post-issue level, $\operatorname{Ln}\left(A_{1}\right)_{[+126,+250]}-\operatorname{Ln}\left(A_{1}\right)_{[-250,-1]}$. Stocks with a larger pre-issue return, smaller companies, larger deals, and SEOs with a lower fraction of primary shares experience a reliably larger increase in the stabilized post-issue demand elasticity. An increase in the number of analysts prior to the offer and a decrease in the lagged bid-ask spread are positively related to a more elastic post-issue stabilized demand curve.

One may question whether the change in $\operatorname{Ln}\left(A_{1}\right)$ is relevant, since the stocks conducting fully marketed offers have higher levels of this variable on average in the pre-issue period, immediately after the SEO, and in the post-issue stabilized period. With these high levels, a large change may be the same percentage change as for the accelerated offers with lower levels of $\operatorname{Ln}\left(A_{1}\right)$. First, it should be noted that the proportional changes in $\operatorname{Ln}\left(A_{1}\right)$ for the fully marketed deals are larger than for accelerated deals (30\% versus $26 \%$ or less). This is true whether we look at univariate changes or (unreported) multiple regression results, in which other determinants of the changes are held constant. Second, and more importantly, it is the change in the slope that determines the benefits of marketing, not the proportional change. In terms of our Fig. 1, the change in the elasticity affects the height of the rectangle that measures the increase in proceeds. If the slope starts out as very flat and gets much flatter, the effect on the height can be smaller than if the slope started out quite steep but changed proportionately less.

\section{Do issuers receive a higher offer price for fully marketed offers?}

We have argued that marketing effort increases the elasticity of the short-run demand curve that an issuing firm faces, allowing it to sell shares at a higher price. Corwin (2003), 
Altinkilic and Hansen (2003), and Mola and Loughran (2004) show that SEOs in the 1990s were typically underpriced by $2-3 \%$ relative to the closing market price on the day of issue. This discounting raises the possibility that marketing might increase the market price without the issuing firm gaining the full benefits in the form of a higher offer price. In this section, we present evidence on the relation of the offer method to both the direct costs (the gross spread) and the indirect costs of underpricing. We also present evidence on how the announcement effect and the number of managing underwriters varies across offer methods.

Table 5 reports the mean and median values for nine offer characteristics, categorized by offer method. The first row shows that, on average, bought deals and accelerated bookbuilt SEOs are offered within one day of the filing. In contrast, fully marketed offers, on average, take 31 calendar days to complete, although there is considerable dispersion. ${ }^{13}$ A longer underwriting process requires more resources and input from both the issuer and the lead manager, which also explains why fully marketed offers pay the highest gross spread.

Bought deals almost always have a sole bookrunner and no co-managers, whereas accelerated bookbuilt offers and fully marketed offers are more likely to have joint bookrunners and multiple co-managers. Prestigious underwriters, as measured by their updated CarterManaster (1990) ranking, predominate among all three of the offer methods.

Fully marketed offers pay the highest average gross spreads, $5.10 \%$, with accelerated bookbuilt offers paying $4.23 \%$, and bought deals paying $2.28 \% .{ }^{14}$ These results are comparable to those reported in previous studies, including Bortolotti, Megginson, and Smart (2008). The difference in gross spread among the three offer methods is significant and important. In a bought deal, the underwriter commits to purchase all of the shares for resale to the secondary market. There is no bookbuilding nor road show involved. The underwriter of a bought deal faces greater resale price risk because, in general, the market has not had a prior opportunity to react to the offer announcement. In an accelerated bookbuilt offer, the lead manager collects

\footnotetext{
${ }^{13}$ Note that the average is affected by several extreme cases. Fourteen fully marketed offers spend more than 180 calendar days. The longest case is the offer by Carmike Cinemas Inc. in 2004. This offer is announced on June 7, 2002 with an expected pricing date of August 5, 2002; revised on July 17, 2002; revised on November 18, 2003; revised on December 16, 2003; and revised on January 14, 2004, before eventually taking place on January 29, 2004. So there are 601 days between the announcement and the offer.

${ }^{14}$ Some bought deals are sold for a net price with no reported gross spread. The gross spread on these deals is assigned a value of zero for computing the average.
} 
price/quantity pairs from institutional investors and underwriters, and then sets the price of the shares in agreement with the issuer using the order book. In fully marketed offers, the lead manager conducts a road show while building the order book. In accelerated bookbuilt offers and fully marketed offers, the offer price is not set until after the market knows about the issue and has reset the stock price, so the underwriter does not assume as much price risk as in bought deals. The risk is smaller in fully marketed offers because investors have more time to value the deal and the underwriter has more time to build the order book.

The evidence in Table 5 suggests that a higher gross spread is associated with bookbuilding and expensive marketing efforts, even though on bought deals the underwriter is exposed to more resale price risk. Unreported multivariate analysis confirms that after controlling for various offer and firm characteristics, fully marketed offers pay an average $3 \%$ higher gross spread than accelerated SEOs. Despite the lower gross spread, an accelerated SEO can still be very lucrative for the underwriter. A typical accelerated deal with $\$ 200$ million in proceeds and a 3\% gross spread generates \$6 million in revenue for the investment bankers in return for just a few days of work.

In Table 5, we also report the pre-offer stock return, announcement effect, price discount, and underpricing. The pre-offer stock return is the buy-and-hold stock return (BHR) calculated over the 250 trading days before the announcement. The announcement effect is the cumulative market-adjusted return estimated over the two-day window $[-1,0], \sum_{t=-1}^{0}\left(r_{i, t}-r_{m, t}\right)$, ending with the announcement date (day 0). ${ }^{15}$ On average, our sample offers experience a significant stock price runup (total return) of $108 \%$ in the year prior to the SEO announcement. This pre-issue return is higher than the average reported in other studies for two reasons. First, there were extremely high pre-issue returns on many tech and internet-related SEOs in the late 1990s. Second, we exclude issuing firms with a market cap that had fallen below $\$ 75$ million at the end of the year over which the runup is measured.

\footnotetext{
${ }^{15}$ Dealogic reports the number of days from the announcement to the offer. We checked several offers and find that if the announcement is made after the market closes and the offer takes place on the next day, Dealogic reports 0 days between the announcement date and the offer date. So the announcement day should be the actual day that the stock price reacts to the announcement. Therefore, unlike most previous studies on the announcement effect, which use other data sources, we exclude the return on the day after the announcement.
} 
On average, there is a $-1.72 \%$ cumulative market-adjusted return around the announcement of the offer. If we use a three-day window, $[-1,1]$, the average market-adjusted return is $-2.1 \%$, which is comparable to the numbers presented in previous studies, as summarized in Ritter (2003, Table 5) and Eckbo, Masulis, and Norli (2007, Table 13).

The pre-offer stock price run-up and announcement effects vary among the three groups. Fully marketed offers experience the largest pre-offer BHR, an average of $118 \%$. Bought deals and accelerated bookbuilt offers experience a smaller average stock price increase, $73 \%$ and $45 \%$, respectively. The difference in pre-issue returns can be partly attributed to the fact that accelerated issuers tend to be big firms, and large firms are less likely to have extreme returns.

Bought deals suffer the least amount of negative market reaction, an average of $-1.49 \%$, and accelerated bookbuilt offers experience an average of $-2.55 \%$. Bought deals and accelerated bookbuilt offers, however, are often announced and underwritten on the same day. Thus, the $[-1,0]$ market-adjusted return includes both the announcement effect and price pressure caused by an inelastic demand curve. Fully marketed offers experience an average announcement effect of $-1.66 \%$, but fully marketed deals tend to have a larger relative size, which would, everything else the same, result in a more negative average market reaction.

Denoting the closing market price on the previous trading day of the offer by $M P_{t-1}$, the offer price by $O P$, and the closing market price on the offer day by $M P_{t}$, the discount is the percentage price change from the closing price on the previous trading day of the offer to the offer price, $\left(\frac{M P_{t-1}-O P}{M P_{t-1}}\right) \times 100 \%$. Underpricing is the percentage price change from the offer price to the closing price on the offer day, $\left(\frac{M P_{t}-O P}{O P}\right) \times 100 \%$. The average discount and underpricing are similar in magnitude. The average SEO in our sample is sold at a $2.75 \%$ price discount and experiences $3.11 \%$ underpricing on the offer day, which is generally consistent with the numbers reported in Altinkilic and Hansen (2003), Corwin (2003), Mola and Loughran (2004), and Chemmanur, $\mathrm{He}$, and $\mathrm{Hu}$ (2009). Both the discount and underpricing levels remain stable during the sample period.

These averages, however, hide important differences across offer methods. Fully marketed offers experience an average discount of $2.66 \%$ and the largest underpricing of $3.43 \%$. 
On average, bought deals have the largest price discount of 3.93\% and the smallest underpricing of $1.09 \%$. This large difference between the price discount and underpricing suggests that the price discount for bought deals is capturing the negative announcement effect. Accelerated bookbuilt offers experience an average discount of $2.43 \%$ and underpricing of $2.10 \%$. If an accelerated offer is priced and offered in a manner such that the announcement effect occurs on the offer date, the two-day announcement effect, $[-1,0]$, can be decomposed into i) the return on the last trading day before the offer, ii) the discount, and iii) the underpricing. We note that 241 of the 290 bought deals and 137 of the 276 accelerated bookbuilt offers are either announced and offered on the same trading day or are announced after the market closes and offered on the next trading day. For this subset of accelerated offers, it is interesting to notice that on average, in unreported results, bought deals experience a positive return of $1.6 \%$ on day -1 while accelerated bookbuilt offers experience a negative return of $-2.6 \%$.

One explanation for these patterns is that issuers may wait for a 'good' day, i.e., with a positive stock return, to conduct a bought deal after the market closes. If there is a tendency to conduct a bought deal after a positive daily stock return, the average announcement effect over the $[-1,0]$ window of $-1.49 \%$ for bought deals would be biased towards zero. For accelerated bookbuilt offers, the day -1 market-adjusted return of $-2.6 \%$ for this subsample suggests that there may be information leakage prior to the announcement of the offer as the deal is discussed with potential underwriters and these underwriters ask institutional investors about their willingness to purchase shares.

The weighted-average underpricing of accelerated offers is $1.58 \%$, which is $1.85 \%$ less than the average underpricing of $3.43 \%$ for fully marketed offers. Fully marketed offers, however, are typically from smaller firms with a higher relative offer size. In unreported results, we regress the gross spread and underpricing on an accelerated offer dummy variable together with other offer and firm characteristic variables, similar to the Eq. (1) specification. A fully marketed offer pays a 3.3\% higher gross spread and experiences underpricing of $1.2 \%$ more than a comparable accelerated offer. The larger underpricing for fully marketed offers suggests that even if the marketing effort boosts the market price, the issuing firm does not get the full benefit of a higher offer price due both to paying a higher gross spread and experiencing more underpricing. 


\section{Conclusion}

The marketing of financial securities is a topic that has been largely ignored in the academic corporate finance literature. We explicitly analyze the offer method decision for follow-on offers in a supply and demand framework in which marketing efforts shift the shortrun demand curve. Other investment banking functions, such as analyst coverage, have been interpreted as being motivated by information production, but as Chung and Jo (1996) and Chahine, Ljungqvist, and Michaely (2008) discuss, these functions also serve the purpose of creating demand.

The recent rise in accelerated SEOs in the U.S. provides an opportunity to study the determinants and economics associated with alternative offer methods. We examine the issuer's choice between an accelerated offer (a bought deal or accelerated bookbuilt offer) and a fully marketed offer. The main differences between accelerated offers and fully marketed offers are that i) there is little or no marketing for accelerated offers, and ii) accelerated offers result in raising equity capital faster. We do not find evidence supporting the desire for speed being an important determinant of the offer method. Instead, we find evidence that firms for which the marketing benefits are larger tend to choose fully marketed offers.

We first develop an analysis of the demand and supply curves for the issuing firm's stock. The issuance represents an increase in the supply. With a downward-sloping demand curve, the stock price decreases due to this increase in supply. Marketing flattens the demand curve and helps to achieve a higher price after the offer. Marketing is not costless, however. Only when the benefits are sufficiently large will a firm choose a costly fully marketed deal in order to increase the elasticity of demand. Therefore, the elasticity of demand is endogenous. The analysis predicts that a fully marketed SEO has greater benefits to the issuing firm when it ex ante faces a highly inelastic demand curve and when the issue size is large.

Our empirical analysis supports our predictions. We use four measures, the order flow inverse demand elasticity $A_{1}$, the arbitrage risk measure $A_{2}$, non-institutional ownership $A_{3}$, and the price impact measure $A_{4}$, to proxy for the demand elasticity. Logit regression results show that the pre-issue elasticity of the issuing firm's demand curve and the offer size (both in absolute and relative terms) are important determinants of the offer method. For an issuing firm 
that is average in other ways, if it has an above-average relative issue size of $30 \%$ of the preissue shares outstanding and ex ante has a relatively inelastic demand curve, with an order flow inverse demand elasticity at the $90^{\text {th }}$ percentile, the probability of using an accelerated offer is only a miniscule $1 \%$. On the other hand, if the issuer has a below average relative offer size of $10 \%$ and an order flow inverse demand elasticity at the $10^{\text {th }}$ percentile, the probability of using an accelerated offer increases dramatically to a sizable $43 \%$.

When we examine the time-series properties of the order flow inverse demand elasticity, we find that in the month after an SEO, demand is much more elastic than before or after. Most importantly, this transitory increase in the demand elasticity is greater for fully marketed deals than accelerated offers. In other words, marketing does increase the elasticity of the short-run demand for the issuer's stock, justifying the higher direct fees incurred by issuing firms that are selling a relatively large number of shares or that face a relatively inelastic short-run demand curve in the absence of marketing efforts.

Our analysis can help explain the worldwide demise of rights offers (Eckbo, Masulis, and Norli, 2007). Unlike fully marketed offers, rights offers typically involve little marketing. In this regard, they are similar to accelerated offers. The drop in the worldwide market share of rights offers has occurred at roughly the same time as the increase in the market share of accelerated offers documented by Bortolotti, Megginson, and Smart (2008). We conjecture that some firms for which the benefits of a fully marketed offer are low have substituted accelerated offers for rights offers. 


\section{Appendix A. Classification of SEO offer method}

Our main database is the Dealogic Equity Capital Markets (ECM) database. Dealogic identifies three major SEO offer methods: accelerated bookbuilt, bought deal, and fully marketed offers. The Thomson Financial Securities Data Company's (SDC) new issues database is more commonly used in academic studies. As pointed out in Bortolotti, Megginson, and Smart (2008), SDC's method of classifying the offering technique is sometimes confusing because it gives multiple designations to the same offer. For example, some offers are classified as "block trade/negotiated sale," "accelerated bookbuilt/firm commitment," or "firm commitment/auction." Dealogic gives a single designation to each offer, so its classification is less ambiguous.

Compared to SDC, Dealogic is more accurate with the filing date and is more consistent with its classification of the offer method. We investigate 519 US seasoned equity offerings during January 1, 2004 to December 31, 2005 listed by both Dealogic and SDC. We first handchecked 35 random offers' filing dates in Dealogic with Factiva and all of them are correct. Dealogic's classification of the offer method is mostly consistent with the time length from filing to offering. Accelerated bookbuilt offers and bought deals are almost always completed within three calendar days from filing with the SEC.

Fully marketed offers take a longer time, ranging from three to more than 150 calendar days. All 68 accelerated bookbuilt offers are completed within three calendar days from filing with the SEC. Among the 119 bought deals, only two offers have a time span longer than three calendar days. One is the offer by Trinity Industries Inc., filed on December 1, 2004, which began trading on December 9, 2004. The Dealogic filing date is consistent with what we find in Factiva. This is a pure secondary offer so it is not included in our study. The other is by Monster Worldwide Inc., offered on January 5, 2004. Monster Worldwide filed several S-3/As during the three months prior to the offer and the last one is filed on January 1, 2004. Among the 331 fully marketed deals, four offers have a time span exceeding 150 calendar days. Two of these four offers' filing dates are consistent with Factiva. Dealogic is apparently wrong with one offer's filing date and it is reclassified as a bought deal. Another offer has an amended file date ten days before the offer so it is still classified as a fully marketed deal. Therefore, we feel comfortable to 
rely mainly on the length of time from filing to the offering, supplemented by Dealogic's classification of the offer method.

Next, we focus on discrepancies between SDC's classification and Dealogic's classification of the offer method. Among the 519 offers, 416 issues' offer methods are classified consistently and 103 are inconsistent. Among the 103 inconsistent offers, 86 offers have consistent offering dates and 17 offers have inconsistent offering dates. If the offering date is consistent, we find that Dealogic's offer method classification is more accurate because all accelerated offers are completed within three days and all fully marketed offers take more than three days to complete. For the 17 offers for which the offering dates are inconsistent, Dealogic's offering dates are correct for 14 out of the 17, where SDC is correct for only three of these cases.

Overall, we conclude that Dealogic is a more reliable database for our study.

\section{Appendix B. Adjustment of trading volume on Nasdaq}

To adjust for institutional features of the way that Nasdaq and NYSE-Amex volume are computed, prior to February 1, 2001, we divide Nasdaq volume by 2.0. This accounts for the practice of counting as trades both trades with market makers and trades among market makers. On February 1, 2001, a "riskless principal" rule went into effect, according to the director of research of Nasdaq and Frank Hathaway, the chief economist of Nasdaq, that resulted in a reduction of approximately 10\% in reported volume. Thus, for February 1, 2001 to December 31, 2001, we divide Nasdaq volume by 1.8. During 2002, securities firms began to charge institutional investors commissions on Nasdaq trades, rather than the prior practice of merely marking up or down the net price, resulting in a further reduction in reported volume of approximately 10\%. Thus, for 2002 and 2003, we divide Nasdaq volume by 1.6. For 2004 and later years, in which much of the volume of Nasdaq (and NYSE) stocks has been occurring on crossing networks and other venues, we use a divisor of 1.0, reflecting the fact that there are no longer important differences in the reporting of Nasdaq and NYSE volume. 


\section{References}

Altinkilic, O., Hansen, R., 2003. Discounting and underpricing in seasoned equity offers. Journal of Financial Economics 69, 285-324.

Asquith, P., Pathak, P., Ritter, J., 2005. Short interest, institutional ownership, and stock returns. Journal of Financial Economics 78, 243-276.

Autore, D., Hutton, I., Kovacs, T., 2008. Certification, firm quality, and seasoned equity offerings. Unpublished working paper, Florida State University and Northeastern University.

Autore, D., Kumar, R., Shome, D., 2008. The revival of shelf-registered corporate equity offerings. Journal of Corporate Finance 14, 32-50.

Baker, M., Coval, J., Stein, J., 2007. Corporate financing decisions when investors take the path of least resistance. Journal of Financial Economics 84, 266-298.

Barber, B., Odean, T., 2008. All that glitters: The effect of attention and news on the buying behavior of individual and institutional investors. Review of Financial Studies 21, 785 818.

Barkley, T., Naranjo, A., Nimalendran, M., 2008. Where's the liquidity? Information and trading costs in asset pricing. Unpublished working paper, Syracuse University and the University of Florida.

Benveniste, L., Spindt, P., 1989. How investment bankers determine the offer price and allocation of new issues. Journal of Financial Economics 24, 343-361.

Bethel, J., Krigman, L., 2008. Managing the costs of issuing common equity: The role of registration choice. Quarterly Journal of Finance and Accounting 47 (4), 57-85.

Bohren, O., Eckbo, B., Michalsen, D., 1997. Why underwrite rights offerings? Some new evidence. Journal of Financial Economics 46, 223-261.

Bortolotti, B., Megginson, W., Smart, S., 2008. The rise of accelerated seasoned equity underwritings. Journal of Applied Corporate Finance 20 (3), 35-57.

Busse, J., Green, C., 2002. Market efficiency in real time. Journal of Financial Economics 65, 413- 437.

Carter, R., Manaster, S., 1990. Initial public offerings and underwriter reputation. Journal of Finance 45, 1045-1067. 
Chacko, G., Jurek, J., Stafford, E., 2008. The price of immediacy. Journal of Finance 63, 12531290.

Chahine, S., Ljungqvist, A., Michaely, R., 2008. Marketing financial claims. Unpublished working paper, Cornell University.

Chemmanur, T., He, S., Hu, G., 2009. The role of institutional investors in seasoned equity offerings. Journal of Financial Economics, 94, 384-411.

Chung, K., Jo, H., 1996. The impact of security analysts' monitoring and marketing functions on the market value of firms. Journal of Financial and Quantitative Analysis 31, 493-512.

Cook, D., Kieschnick, R., Van Ness, R., 2006. On the marketing of IPOs. Journal of Financial Economics 82, 35-61.

Corwin, S., 2003. The determinants of underpricing for seasoned equity offers. Journal of Finance 58, 2249-2279.

Corwin, S., Schultz, P., 2005. The role of IPO underwriting syndicates: Pricing, information production, and underwriter competition. Journal of Finance 60, 443-486.

Duffie, D., 2010. Asset price dynamics with slow moving capital. Journal of Finance, forthcoming.

Eckbo, B., Masulis, R., 1992. Adverse selection and the rights offer paradox. Journal of Financial Economics 32, 293-332.

Eckbo, B., Masulis, R., Norli, O., 2007. Security offerings. In: Eckbo, B.E. (Ed.)., Handbook of Corporate Finance: Empirical Corporate Finance, Vol. $1 \mathrm{~b}$ (Chapter 6). Elsevier, NorthHolland, pp. 233-373.

Greenwood, R., 2005. Short- and long-term demand curves for stocks: Theory and evidence on the dynamics of arbitrage. Journal of Financial Economics 75, 607- 649.

Greenwood, R., 2008. Excess comovement of stock returns: Evidence from cross-sectional variation in Nikkei 225 weights. Review of Financial Studies 21, 1153-1186.

Hodrick, L., 1999. Does stock price elasticity affect corporate financial decisions? Journal of Financial Economics 52, 225-256.

Hong, H., Stein, J., 2007. Disagreement and the stock market. Journal of Economic Perspectives $21,109-128$.

Huang, R., Zhang, D., 2010. Managing underwriters and the marketing of seasoned equity offerings. Journal of Financial and Quantitative Analysis, forthcoming. 
Intintoli, V., Kahle, K., 2009. Seasoned equity offers: The effect of insider ownership and float. Unpublished working paper, Southern Illinois University Carbondale.

Kalay, A., Sade, O., Wohl, A., 2004. Measuring stock illiquidity: An investigation of the demand and supply schedules at the TASE. Journal of Financial Economics 74, 461- 486.

Liu, L., Sherman, A., Zhang, Y., 2008. The role of the media in initial public offerings. Working paper, Hong Kong University of Science \& Technology.

Loderer, C., Cooney, J., Van Drunen, L., 1991. The price elasticity of demand for common stock. Journal of Finance 46, 621-651.

Meidan, D., 2005. A re-examination of price pressure around seasoned equity offerings. Working paper. Northwestern University.

Merton, R., 1987. A simple model of capital market equilibrium with incomplete information. Journal of Finance 42, 483-510.

Miller, E., 1977. Risk, uncertainty, and divergence of opinion. Journal of Finance 32, 1151-1168.

Mola, S., Loughran, T., 2004. Discounting and clustering in seasoned equity offering prices. Journal of Financial and Quantitative Analysis 39, 1-23.

Myers, S. , Majluf, N., 1984. Corporate financing and investment decisions when firms have information that investors do not have. Journal of Financial Economics 13, 187-221.

Rinne, K., Suominen, M., 2008. Value uncertainty, price impact and the choice of the equity issuing method. Working paper, Helsinki School of Economics.

Ritter, J., 2003. Investment banking and securities issuance. In: Constantinides, G., Harris, M., Stulz, R. (Eds). Handbook of the Economics of Finance (Chapter 5). Elsevier, NorthHolland, pp. 255-306..

Smith, Jr., C., 1977. Alternative methods for raising capital: Rights vs. underwritten offers. Journal of Financial Economics 5, 273-307.

Wurgler, J., Zhuravskaya, E., 2002. Does arbitrage flatten demand curves for stocks? Journal of Business 75, 582-608.

Yuan, Y., 2008. Attention and trading. Working paper, University of Iowa.

Zhang, D., 2004. Why do IPO underwriters allocate extra shares when they expect to buy them back? Journal of Financial and Quantitative Analysis 39, 571-594. 


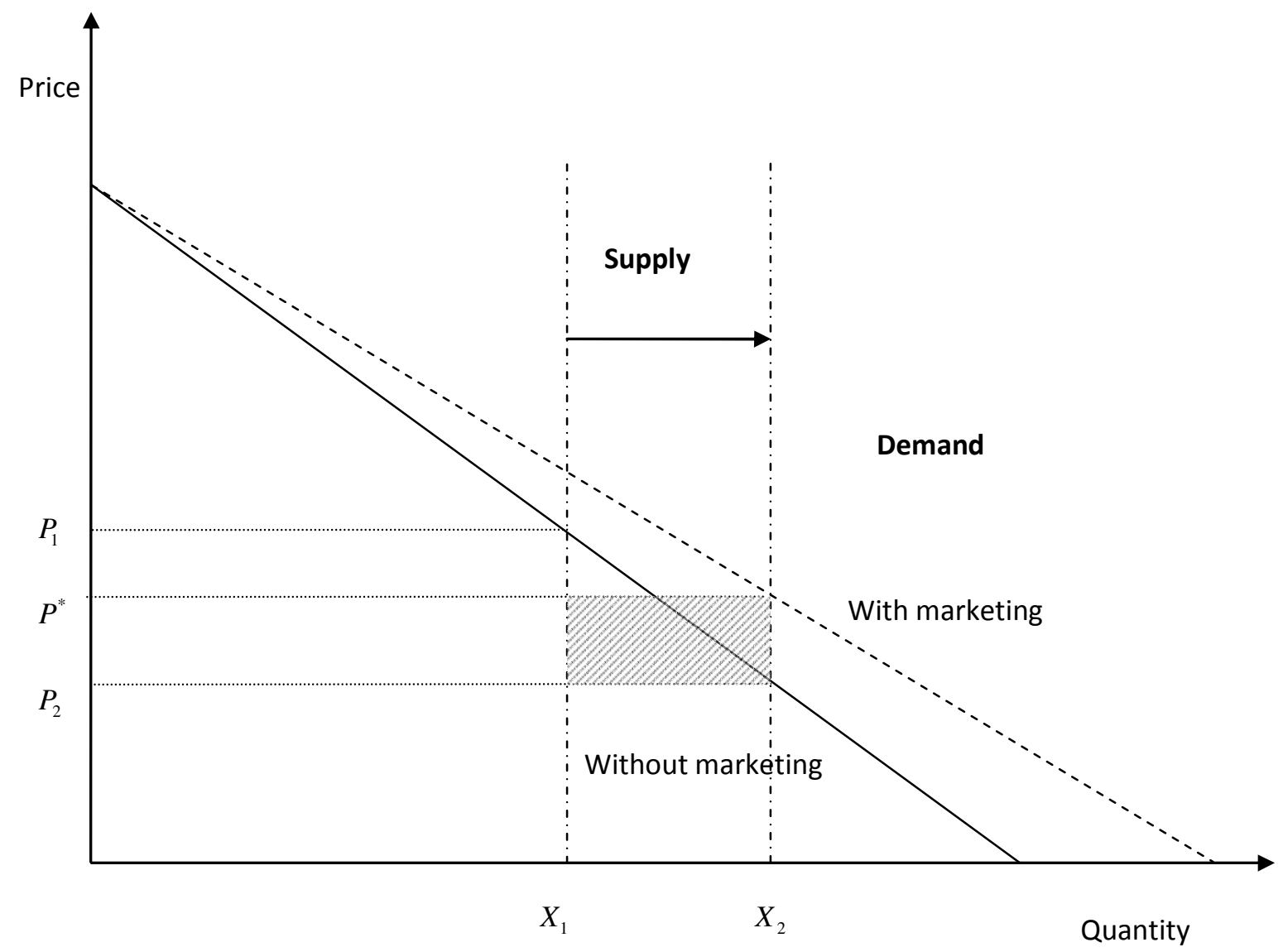

Fig. 1. Comparison of demand curves with and without marketing. The solid line is the demand curve for the issuing firm's stock before the offer. The dashed line represents the short-run demand curve for the stock if the offer is fully marketed. It becomes more elastic than the ex ante demand curve because marketing flattens the demand curve. Therefore, the post-issue price is higher at $P^{*}$ instead of $P_{2}$ if there is no marketing. The shaded rectangular area represents the issuer's gross proceeds gain from marketing the offer. $X_{1}$ is the supply of shares prior to the offer, and $X_{2}$ is the post-issue number of shares. 


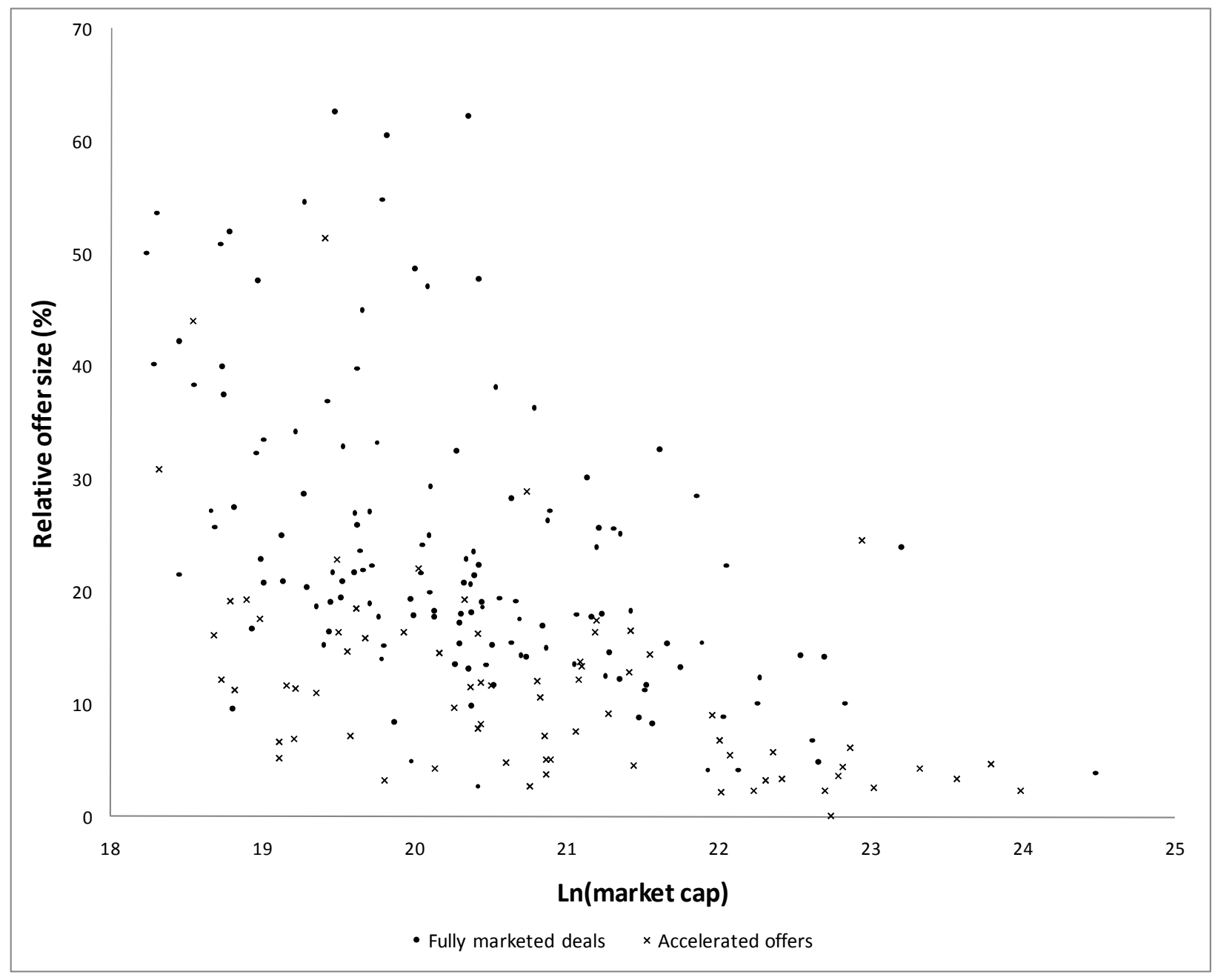

Fig. 2. Scatter diagram relating relative offer size to $\operatorname{Ln}($ market capitalization). The sample consists of 211 SEOs in 2007. Market capitalization is computed as the pre-issue market cap of equity. $\operatorname{Ln}\left(\right.$ market capitalization) ranges from $\$ 77.3$ million, $e^{18.16}$, to $\$ 42.6$ billion, $e^{24.48}$. The percentage relative offer size is the number of shares offered divided by the number of shares outstanding prior to the offer. The farthest lower right dot represents Schering-Plough Corp.'s fully marketed SEO in August 2007, with a relative offer size of 3.86\%. 


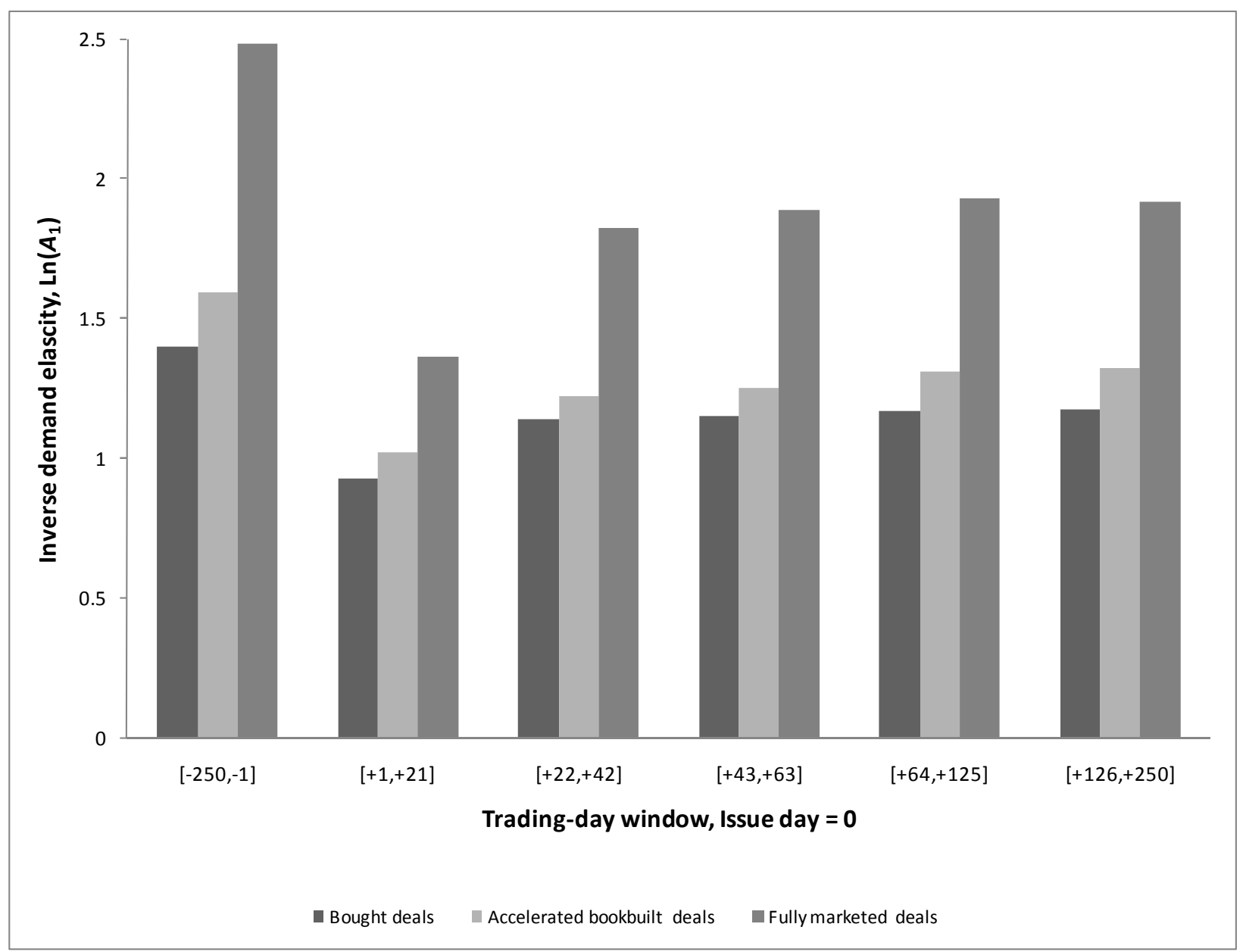

Fig. 3. Pre- and post-issue order flow inverse demand elasticities. The bar chart graphs the average pre- and post-issue values of $\operatorname{Ln}\left(A_{1}\right)$, our first proxy for demand elasticity, for the three SEO offer method groups. $A_{1}$ is the average order flow inverse demand elasticity. A lower value of $A_{1}$ indicates more elastic demand. The issue day is day 0 . The pre-issue trading day window is the 250 trading days prior to the issue, [-250,-1]. The five consecutive post-issue trading-day windows are $[+1,+21],[+22,+42],[+43,+63],[+64,+125]$, and $[+126,+250]$. The sample is composed of 3,276 SEOs from $1996-2007$. 


\section{Table 1}

Sample summary statistics

The sample includes 3,276 seasoned equity offerings in Dealogic's ECM Analytics Database during 1996 to 2007. The issuer must be a US-based company listed on Nasdaq, the American Stock Exchange (Amex), or the New York Stock Exchange (NYSE). ADRs and ADSs, private placements, rights offers, best efforts, non SEC-registered offers, Rule 144A offers, units, closed-end funds, REITs, and pure secondary offerings are excluded. We also exclude 35 non-shelf takedown offers that are identified by Dealogic as bought deals or accelerated bookbuilt offers. The is suer must have more than a $\$ 75$ million market capitalization before the offer. Furthermore, the issuing firm must be present on the University of Chicago Center for Research in Security Prices (CRSP) database on the day before the announcement day, the offer day, and the first trading day after the issue. Panel A reports the number of SEOs and aggregate proceeds by year and offering method. Total proceeds is the total amount of dollars (in billions) raised globally including exercised overallotment shares in all tranches. Total proceeds are adjusted for inflation and reported in 2007 purchasing power. Panel B lists the number of shelf-takedown and nonshelf takedown offers that are bought deals, accelerated offers, and fully marketed offers.

Panel A: Number of seasoned equity offerings (SEOS) and aggregate proceeds by year and offering method

\begin{tabular}{|c|c|c|c|c|c|c|c|c|}
\hline \multirow[b]{2}{*}{ Year } & \multicolumn{2}{|c|}{ Sample SEOs } & \multicolumn{2}{|c|}{ Bought deals } & \multicolumn{2}{|c|}{$\begin{array}{c}\text { Accelerated } \\
\text { bookbuilt SEOs }\end{array}$} & \multicolumn{2}{|c|}{ Fully marketed SEOs } \\
\hline & Number & $\begin{array}{c}\text { Total } \\
\text { proceeds } \\
\text { (\$ billion) }\end{array}$ & Number & $\begin{array}{c}\text { Total } \\
\text { proceeds } \\
\text { (\$ billion) }\end{array}$ & Number & $\begin{array}{c}\text { Total } \\
\text { proceeds } \\
(\$ \text { billion })\end{array}$ & Number & $\begin{array}{c}\text { Total } \\
\text { proceeds } \\
(\$ \text { billion })\end{array}$ \\
\hline 1996 & 400 & 57.33 & 1 & 0.08 & 0 & 0.00 & 399 & 57.24 \\
\hline 1997 & 359 & 54.66 & 2 & 0.76 & 8 & 2.37 & 349 & 51.53 \\
\hline 1998 & 250 & 51.76 & 8 & 2.95 & 2 & 0.16 & 240 & 48.65 \\
\hline 1999 & 298 & 79.08 & 19 & 6.19 & 2 & 0.80 & 277 & 72.08 \\
\hline 2000 & 311 & 105.50 & 27 & 6.31 & 2 & 0.16 & 282 & 99.03 \\
\hline 2001 & 232 & 58.40 & 35 & 11.50 & 17 & 2.65 & 180 & 44.25 \\
\hline 2002 & 223 & 51.83 & 25 & 7.50 & 41 & 14.18 & 157 & 30.15 \\
\hline 2003 & 254 & 47.78 & 36 & 10.31 & 42 & 8.93 & 176 & 28.55 \\
\hline 2004 & 283 & 50.39 & 35 & 8.10 & 51 & 11.94 & 197 & 30.35 \\
\hline 2005 & 219 & 39.27 & 32 & 7.00 & 29 & 5.66 & 158 & 26.60 \\
\hline 2006 & 236 & 38.15 & 43 & 7.35 & 36 & 7.39 & 157 & 23.40 \\
\hline 2007 & 211 & 41.44 & 27 & 3.95 & 46 & 8.72 & 138 & 28.78 \\
\hline
\end{tabular}

Panel B: Shelf-takedown SEOs versus non-shelftakedown SEOs

\begin{tabular}{lcccc}
\hline & All SEOs & Bought deals & $\begin{array}{c}\text { Accelerated } \\
\text { bookbuilt SEOs }\end{array}$ & Fully marketed SEOs \\
\hline $\begin{array}{l}\text { Shelf- } \\
\text { takedowns }\end{array}$ & 1,332 & 290 & 276 & 766 \\
$\begin{array}{l}\text { Non-shelf } \\
\text { offers }\end{array}$ & 1,944 & 0 & 0 & 1,944 \\
\hline
\end{tabular}




\section{Table 2}

Summary statistics of offer characteristics and demand elasticity proxies of SEOs, 1996 to 2007

Panel A lists means and medians [in brackets] of offer characteristics. Panel B reports the raw values and the natural $\log$ transformed values of the four demand elasticity proxies, $A_{1}, A_{2}, A_{3}$, and $A_{4}$. Market capitalization is the market capitalization of equity (in millions) on the last day prior to the announcement of the offer for the share class that is being issued. Proceeds is the total amount (in millions of dollars) rais ed globally including exercised overallotment shares in all tranches. Both are adjusted for inflation and reported in dollars of 2007 purchasing power. Relative offer size equals offered shares divided by shares outstanding prior to the is sue. Fraction of primary shares equals primary (new) shares divided by the total number of shares offered. The number of analysts following the is suer's stock is obtained from the IBES database. We include analysts who post one or more recommendations within 12 months before the offer. Bid-ask spread (\%) is the average daily bid-ask spread, scaled by the stock price, over the 250 trading days prior to the announcement date. The average daily order flow inverse demand elasticity, $A_{1}$, is defined as the absolute value of the daily raw return (in decimal form) divided by the daily turnover, averaged over 250 trading days before the announcement date. Turnover is the trading volume divided by the number of shares outstanding. The trading volume of Nasdaqlisted stocks is adjusted in a manner described in Appendix B. The arbitrage risk measure, $A_{2}$, is the residual variance, expressed as a squared percentage of the market model OLS regression residual estimated over the 250 trading days before the announcement date. $A_{3}$ is $100 \% \times(1$ - institutional ownership), where the institutional ownership fraction is constructed from Thoms on Reuters' CDA/Spectrum Institutional (13f) Holdings database at the end of the latest quarter prior to the SEO offer date. $A_{3}$ is winsorized at $0 \%$ and $90 \% . A_{4}$ is the median daily price impact measure over [-15,-1] prior to the announcement estimated using TAQ data. $A_{4}$ is detrended by subtracting the yearly sample average values. A constant of 100 is added to $\mathrm{A}_{4}$ before the $\log$ transformation to avoid negative values. $p$-values for the non-parametric $t$-test (Kruskal-Wallis test) and the Chi-squared statistics for the median are reported in the last column. We use the K-W test to test the hypothesis that the average of the bought deals and accelerated bookbuilt SEOs is equal to the average for fully marketed deals. The K-W test does not require the variable to be normally distributed. The test for the medians is the nonparametric median $\chi 2$ test (Brown-Mood test).

Panel A: Offer characteristics

\begin{tabular}{lcccccc}
\hline & All SEOs & $\begin{array}{c}\text { Bought } \\
\text { deals }\end{array}$ & $\begin{array}{c}\text { Accelerated } \\
\text { bookbuilt } \\
\text { SEOs }\end{array}$ & $\begin{array}{c}\text { Fully } \\
\text { marketed } \\
\text { SEOs }\end{array}$ & $\begin{array}{c}\text { Difference } \\
\text { accelerated - fully } \\
\text { marketed }\end{array}$ & $\begin{array}{c}\mathrm{K}-\mathrm{W} \\
{[\chi 2]} \\
p \text {-values }\end{array}$ \\
\hline Number & 3,276 & 290 & 276 & 2,710 & - & \\
& & & & & & \\
Pre-offer market & 2,193 & 5,218 & 4,690 & 1,615 & 3,345 & 0.00 \\
capitalization $(\$ \mathrm{M})$ & {$[640]$} & {$[1,778]$} & {$[1,192]$} & {$[554]$} & {$[887]$} & {$[0.00]$} \\
Proceeds $(\$ M)$ & 206 & 248 & 228 & 199 & 39 & 0.87 \\
& {$[113]$} & {$[149]$} & {$[94]$} & {$[112]$} & {$[5]$} & {$[0.58]$} \\
Relative offer size $(\%)$ & 22.5 & 9.3 & 11.4 & 25.1 & -14.8 & 0.00 \\
& {$[18.9]$} & {$[7.5]$} & {$[9.9]$} & {$[21.5]$} & {$[-12.8]$} & {$[0.00]$} \\
Fraction of primary & 85.0 & 98.8 & 98.6 & 82.1 & 16.6 & 0.00 \\
shares $(\%)$ & {$[100]$} & {$[100]$} & {$[100]$} & {$[100]$} & {$[0]$} & {$[0.00]$} \\
Number of analysts & 5.08 & 8.64 & 7.21 & 4.48 & 3.47 & 0.00 \\
& {$[4]$} & {$[8]$} & {$[6]$} & {$[4]$} & {$[3]$} & {$[0.00]$} \\
Bid-ask spread $(\%)$ & 1.47 & 0.68 & 0.61 & 1.64 & -1.00 & 0.00 \\
& {$[1.03]$} & {$[0.35]$} & {$[0.40]$} & {$[1.29]$} & {$[-0.92]$} & {$[0.00]$} \\
\hline
\end{tabular}


Table 2 (continued)

\begin{tabular}{|c|c|c|c|c|c|c|}
\hline \multicolumn{7}{|c|}{ Panel B: Demand elasticity proxies } \\
\hline & All SEOs & $\begin{array}{c}\text { Bought } \\
\text { deals }\end{array}$ & $\begin{array}{c}\text { Accelerated } \\
\text { bookbuilt } \\
\text { SEOs } \\
\end{array}$ & $\begin{array}{c}\text { Fully } \\
\text { marketed } \\
\text { SEOs } \\
\end{array}$ & $\begin{array}{c}\text { Difference } \\
\text { accelerated - } \\
\text { fully marketed }\end{array}$ & $\begin{array}{c}\mathrm{K}-\mathrm{W} \\
{[\chi 2]} \\
p \text {-values } \\
\end{array}$ \\
\hline \multirow[t]{2}{*}{ Raw value of $A_{1}$} & 24.83 & 8.77 & 7.61 & 28.31 & -20.10 & 0.00 \\
\hline & [7.61] & {$[3.15]$} & {$[3.40]$} & [9.23] & {$[-5.96]$} & {$[0.00]$} \\
\hline \multirow[t]{2}{*}{$\operatorname{Ln}\left(A_{1}\right)$} & 2.18 & 1.24 & 1.39 & 2.37 & -1.06 & 0.00 \\
\hline & {$[2.03]$} & [1.15] & [1.22] & [2.22] & {$[-1.04]$} & {$[0.00]$} \\
\hline \multirow[t]{2}{*}{ Raw value of $A_{2}$} & 16.93 & 11.21 & 10.72 & 18.17 & -7.20 & 0.00 \\
\hline & {$[10.57]$} & {$[6.74]$} & [4.99] & [11.64] & {$[-5.91]$} & {$[0.00]$} \\
\hline \multirow[t]{2}{*}{$\operatorname{Ln}\left(A_{2}\right)$} & 2.31 & 1.82 & 1.71 & 2.42 & -0.65 & 0.00 \\
\hline & {$[2.36]$} & [1.91] & [1.61] & [2.45] & {$[-0.71]$} & {$[0.00]$} \\
\hline \multirow[t]{2}{*}{ Raw value of $A_{3}$} & 54.02 & 36.25 & 45.75 & 56.77 & -15.88 & 0.00 \\
\hline & [56.95] & [32.70] & [47.61] & [60.65] & {$[-20.56]$} & {$[0.00]$} \\
\hline \multirow[t]{2}{*}{$\operatorname{Ln}\left(A_{3}\right)$} & 3.78 & 3.23 & 3.51 & 3.87 & -0.50 & 0.00 \\
\hline & {$[4.04]$} & {$[3.49]$} & {$[3.86]$} & [4.11] & {$[-0.41]$} & {$[0.00]$} \\
\hline \multirow[t]{2}{*}{ Detrended $A_{4}$} & 0.01 & -0.09 & -1.48 & 0.17 & -0.94 & 0.00 \\
\hline & {$[-0.54]$} & {$[-1.83]$} & {$[-2.21]$} & {$[-0.40]$} & {$[-1.59]$} & {$[0.00]$} \\
\hline \multirow[t]{2}{*}{$\operatorname{Ln}\left(100+A_{4}\right)$} & 4.603 & 4.600 & 4.588 & 4.605 & -0.01 & 0.00 \\
\hline & {$[4.60]$} & [4.59] & {$[4.58]$} & [4.60] & {$[-0.02]$} & {$[0.00]$} \\
\hline
\end{tabular}


Table 3

Binomial logistic regression, determinants of offering method for SEOs, 1996 - 2007

The regression tests the main hypothesis in equation (1). The dependent variable is the offering method. It is a dichotomous variable for which accelerated deals, including bought deals and accelerated bookbuilt offers, equal 1 , and fully marketed offers equal 0 . We apply log transformation on the inflation-adjusted market cap and proceeds, the bid-ask spread, and the number of analysts to control for extreme values in these variables. We detrend the log bid-ask spreads by subtracting the sample average log bid-ask spread within the same calendar year. The rest of the explanatory variables are defined in Table 2 . Note that the relative offer size and the fraction of primary shares are ratios, not percentages. We report two marginal effects to the right of the estimates. The first is calculated at the sample medians. For each explanatory variable, it is the difference in the two probabilities when we increase and decrease the variable's value by 0.5 standard deviation from the median and hold the rest of the variables at their median levels. The second is calculated in a similar way but instead of the sample medians, we hold $\operatorname{Ln}\left(A_{1}\right), \operatorname{Ln}\left(A_{2}\right), \operatorname{Ln}\left(A_{3}\right), \operatorname{Ln}\left(100+A_{4}\right)$, the offer proceeds, and the relative offer size at the 25th percentile, and the market capitalization, the primary fraction, the bid-ask spread, and the number of analysts at the 75th percentile. The $t$-statistics are in parentheses. The $R$-squared is the likelihood-based pseudo $R$-squared measure.

Dependent variable: Accelerated offer dummy

\begin{tabular}{|c|c|c|c|c|}
\hline & \multirow{2}{*}{ Es timate } & \multicolumn{2}{|c|}{ Marginal effect (\%) } & \multirow{2}{*}{$\begin{array}{l}\text { Standard } \\
\text { deviation }\end{array}$} \\
\hline & & At the medians & $25 / 75$ th percentile & \\
\hline $\operatorname{Ln}\left(A_{1}\right)$ & $\begin{array}{r}-0.79 \\
(-9.61)\end{array}$ & -9.99 & -20.52 & 1.26 \\
\hline $\operatorname{Ln}\left(A_{2}\right)$ & $\begin{array}{r}-0.20 \\
(-3.49)\end{array}$ & -2.05 & -4.32 & 1.06 \\
\hline $\operatorname{Ln}\left(A_{3}\right)$ & $\begin{array}{r}-0.17 \\
(-2.63)\end{array}$ & -1.42 & -2.99 & 0.83 \\
\hline $\operatorname{Ln}\left(100+A_{4}\right)$ & $\begin{array}{r}0.23 \\
(0.25)\end{array}$ & 0.14 & 0.29 & 0.06 \\
\hline $\operatorname{Ln}(\mathrm{MV})$ & $\begin{array}{r}0.53 \\
(2.80)\end{array}$ & 6.65 & 13.85 & 1.26 \\
\hline $\operatorname{Ln}($ Proceeds $)$ & $\begin{array}{r}-1.01 \\
(-5.01)\end{array}$ & -5.04 & -20.12 & 0.98 \\
\hline Relative offer size & $\begin{array}{r}-8.25 \\
(-4.89)\end{array}$ & -15.84 & -31.37 & 0.19 \\
\hline Fraction of primary shares & $\begin{array}{r}4.32 \\
(6.47)\end{array}$ & 4.31 & 12.34 & 0.25 \\
\hline Ln(1 + Analysts $)$ & $\begin{array}{r}0.56 \\
(5.00)\end{array}$ & 3.97 & 8.33 & 0.72 \\
\hline Detrended Ln(bid-ask spread) & $\begin{array}{r}0.52 \\
(4.80)\end{array}$ & 3.70 & 7.77 & 0.72 \\
\hline Intercept & $\begin{array}{r}3.75 \\
(0.85)\end{array}$ & - & - & - \\
\hline Number of SEOs & 3,276 & & & \\
\hline$R$-squared & 0.296 & & & \\
\hline
\end{tabular}




\section{Table 4}

Change in demand elasticity for U.S. SEOs from 1996 - 2007

Panel A reports the mean pre-issue and post-issue values of $\operatorname{Ln}\left(A_{1}\right)$, the order flow inverse demand elasticity. The postissue $\operatorname{Ln}\left(A_{1}\right)$ is estimated over $[+1,+21],[+22,+42],[+43,+63],[+64,+125]$, and $[+126,+250]$ trading day windows after the offer, or if less than the required trading days are available, all available day s on CRSP ending December 31, 2008. Panel B compares the mean pre-issue and post-issue values ( $t$-statistics in parentheses) of $\operatorname{Ln}\left(A_{1}\right)$. The Kruskal-Wallis (KW) statistic tests the hypothesis that the average change for the bought deals and accelerated bookbuilt SEOs combined is equal to the average change for fully marketed deals. Panel C reports OLS regression results with the change in $\operatorname{Ln}\left(A_{1}\right)$, the difference between pre-issue $\operatorname{Ln}\left(A_{1}\right)$ and post-issue $\operatorname{Ln}\left(A_{1}\right)$, as the dependent variable. A large increase in the absolute value of the elasticity (a decrease in the inverse elasticity) from the pre-issue to the post-issue period is measured as a positive number. Fully marketed is a dummy variable that equals one for a fully marketed offer and equals zero for an accelerated offer. The change in the logged number of analy sts that cover the stock is measured as $\operatorname{Ln}(1+$ analy sts $)$ in $[-125,-1]-\operatorname{Ln}(1+$ analy sts $)$ in $[-$ $250,-126]$ prior to the announcement. The change in logged average bid-ask spread is measured as $\operatorname{Ln}$ (bid-ask spread) in [-125,1] - Ln(bid-ask spread) in [-250,-126]. We do not detrend the bid-ask spread as in Table 3. The rest of the variables are defined the same as in Table 3. The sample size in Panel C is $8.2 \%$ smaller than in panel A because we exclude SEOs whose bid-ask spread data are not available in the CRSP files on trading day s [-250,-126] prior to the announcement. Since, especially in the early years of our sample, most SEOs were announced approximately two months before the offer date, very few SEOs that occurred within eight months of the IPO date are included in the regressions. We lose 279 observations for this and related reasons that are needed for computing the difference between trading day s $[-250,-126]$ and $[-125,-1]$. The $t$-statistics are in parentheses.

Panel A: Pre- and post-issue values of $\operatorname{Ln}\left(A_{1}\right)$

\begin{tabular}{|c|c|c|c|c|c|}
\hline & All SEOs & $\begin{array}{l}\text { Bought } \\
\text { deals }\end{array}$ & $\begin{array}{l}\text { Accelerated } \\
\text { bookbuilt } \\
\text { SEOs }\end{array}$ & $\begin{array}{c}\text { Fully } \\
\text { marketed } \\
\text { SEOs }\end{array}$ & $\begin{array}{c}p \text {-value from } \\
\text { KW-test } \\
\text { statistic }\end{array}$ \\
\hline Number & 3,276 & 290 & 276 & 2,710 & \\
\hline Pre-is sue $\operatorname{Ln}\left(A_{1}\right):[-250,-1]$ & 2.18 & 1.24 & 1.39 & 2.37 & - \\
\hline Post-issue $\operatorname{Ln}\left(A_{1}\right):[+1,+21]$ & 1.14 & 0.75 & 0.79 & 1.22 & - \\
\hline$[+22,+42]$ & 1.56 & 0.96 & 0.98 & 1.68 & \\
\hline$[+43,+63]$ & 1.61 & 0.97 & 1.00 & 1.74 & \\
\hline$[+64,+125]$ & 1.64 & 0.99 & 1.06 & 1.77 & \\
\hline$[+126,+250]$ & 1.63 & 0.98 & 1.06 & 1.75 & - \\
\hline \multicolumn{6}{|c|}{ Panel B: Changes in the mean values of $\operatorname{Ln}\left(A_{1}\right)$} \\
\hline $\begin{array}{l}\text { Percentage change } 1 \text { : } \\
\qquad([+126,+250]-[+1,+21]) /[+126,+250]\end{array}$ & $30 \%$ & $23 \%$ & $26 \%$ & $30 \%$ & \\
\hline $\begin{array}{c}\text { Change } 1:[+126,+250]-[+1,+21] \\
t \text {-statistics }\end{array}$ & $\begin{array}{c}0.49 \\
(37.42)\end{array}$ & $\begin{array}{c}0.23 \\
(7.37)\end{array}$ & $\begin{array}{c}0.27 \\
(7.20)\end{array}$ & $\begin{array}{c}0.53 \\
(36.45)\end{array}$ & 0.00 \\
\hline $\begin{array}{c}\text { Change } 2:[+126,+250]-[+22,+42] \\
t \text {-statistics }\end{array}$ & $\begin{array}{c}0.07 \\
(6.05)\end{array}$ & $\begin{array}{c}0.02 \\
(0.74)\end{array}$ & $\begin{array}{c}0.08 \\
(2.20)\end{array}$ & $\begin{array}{c}0.07 \\
(5.66)\end{array}$ & 0.41 \\
\hline $\begin{array}{c}\text { Change } 3:[+126,+250]-[+43,+63] \\
t \text {-statistics }\end{array}$ & $\begin{array}{c}0.02 \\
(1.80)\end{array}$ & $\begin{array}{c}0.01 \\
(0.38)\end{array}$ & $\begin{array}{c}0.05 \\
(1.63)\end{array}$ & $\begin{array}{c}0.02 \\
(1.39)\end{array}$ & 0.64 \\
\hline $\begin{array}{c}\text { Change } 4:[+126,+250]-[+64,+125] \\
t \text {-statistics }\end{array}$ & $\begin{array}{c}-0.01 \\
(-1.72)\end{array}$ & $\begin{array}{c}0.00 \\
(-0.06)\end{array}$ & $\begin{array}{c}0.00 \\
(0.06)\end{array}$ & $\begin{array}{l}-0.02 \\
(-1.81)\end{array}$ & 0.70 \\
\hline $\begin{array}{c}\text { Change } 5:[+126,+250]-[-250,-1] \\
t \text {-statistics }\end{array}$ & $\begin{array}{c}-0.56 \\
(-32.36)\end{array}$ & $\begin{array}{l}-0.25 \\
(-7.91)\end{array}$ & $\begin{array}{c}-0.33 \\
(-7.50)\end{array}$ & $\begin{array}{c}-0.61 \\
(-30.85)\end{array}$ & 0.00 \\
\hline
\end{tabular}


Table 4 (continued)

Panel C: OLS regression results

\begin{tabular}{|c|c|c|}
\hline & \multicolumn{2}{|c|}{ Dependent variable: Change in $\operatorname{Ln}\left(\mathrm{A}_{1}\right)$} \\
\hline & {$[+126,+250]-[+1,+21]$} & {$[+126,+250]-[-250,-1]$} \\
\hline \multirow[t]{2}{*}{ Fully marketed dummy } & 0.11 & -0.07 \\
\hline & $(2.89)$ & $(-1.50)$ \\
\hline \multirow[t]{2}{*}{ Ln(Pre-offer stock return) } & -0.04 & -0.04 \\
\hline & $(-3.85)$ & $(-3.39)$ \\
\hline \multirow[t]{2}{*}{$\operatorname{Ln}(\mathrm{MV})$} & -0.22 & 0.26 \\
\hline & $(-8.62)$ & $(8.54)$ \\
\hline \multirow[t]{2}{*}{ Ln(Proceeds $)$} & 0.13 & -0.15 \\
\hline & $(4.58)$ & $(-4.47)$ \\
\hline \multirow[t]{2}{*}{ Relative offer size } & 0.23 & 0.11 \\
\hline & $(2.39)$ & $(0.97)$ \\
\hline \multirow[t]{2}{*}{ Fraction of primary shares } & 0.11 & 0.55 \\
\hline & $(1.98)$ & $(8.07)$ \\
\hline \multirow[t]{2}{*}{$\operatorname{Ln}(1+$ analysts $)[-125,-1]-\operatorname{Ln}(1+$ analysts $)[-250,-126]$} & 0.01 & -0.06 \\
\hline & $(0.47)$ & $(-2.33)$ \\
\hline \multirow[t]{2}{*}{$\operatorname{Ln}($ bid-ask spread) $[-125,-1]-\operatorname{Ln}($ bid-ask spread) $[-250,-126]$} & 0.08 & 0.50 \\
\hline & $(2.62)$ & $(13.00)$ \\
\hline \multirow[t]{2}{*}{ Intercept } & 2.28 & -3.44 \\
\hline & $(8.60)$ & $(-10.71)$ \\
\hline Number of SEOs & 2,998 & 2,998 \\
\hline$R$-squared & 0.11 & 0.17 \\
\hline
\end{tabular}


Table 5

Summary statistics of offer characteristics

Table 5 reports means and medians [in brackets] of offer characteristics. Number of days from filing to offer is the number of calendar days between the filing date and the offer date. Number of bookrunners is the number of bookrunners on the is sue. Bookrunner reputation is the bookrunner's Carter-Manaster (1990) ranking obtained from Jay Ritter's web page. If there are multiple bookrunners, we use the maximum ranking among all the bookrunners. Number of co-managers is the number of co-managers on the is sue. Gross spread is the underwriting discount as a percentage of the offer price. Pre-offer return is the buy-and-hold percentage stock return during the 250 trading days, [-250, -1], ending with the announcement date. Announcement effect is the cumulative market-adjusted percentage return during the two-day window, $[-1,0]$, ending with the announcement date. Discount is the percentage change from the closing price on the day before the offer to the offer price. Underpricing is the percentage increase from the offer price to the closing price on the offer day. $p$-values for the non-parametric $t$-test (Kruskal-Wallis test) and the $\chi^{2}$ statistics for the median are reported in the last column. We use the K-W test to test the hypothes is that the average of the bought deals and accelerated bookbuilt SEOs is equal to the average for fully marketed deals. The K-W test does not require the variable to be normally distributed. The test for the medians is the non-parametric median $\chi 2$ test (Brown-Mood test).

\begin{tabular}{lcccccc}
\hline & All SEOs & $\begin{array}{c}\text { Bought } \\
\text { deals }\end{array}$ & $\begin{array}{c}\text { Accelerated } \\
\text { bookbuilt } \\
\text { SEOs }\end{array}$ & $\begin{array}{c}\text { Fully } \\
\text { marketed } \\
\text { SEOs }\end{array}$ & $\begin{array}{c}\text { Difference } \\
\text { accelerated - } \\
\text { fully marketed }\end{array}$ & $\begin{array}{c}\text { K-W } \\
{[\chi 2]} \\
p \text {-values }\end{array}$ \\
\hline Number of days from & 26 & 0 & 1 & 31 & -31 & 0.00 \\
filing to offer & {$[21]$} & {$[0]$} & {$[1]$} & {$[25]$} & {$[-25]$} & {$[0.00]$} \\
Number of bookrunners & 1.19 & 1.06 & 1.49 & 1.17 & 0.09 & 0.00 \\
& {$[1]$} & {$[1]$} & {$[1]$} & {$[1]$} & {$[0]$} & {$[0.01]$} \\
Bookrunner reputation & 8.25 & 8.35 & 7.98 & 8.27 & -0.09 & 0.67 \\
& {$[9]$} & {$[9]$} & {$[9]$} & {$[9]$} & {$[0]$} & {$[0.88]$} \\
Number of co-managers & 2.30 & 0.13 & 2.39 & 2.53 & -1.30 & 0.00 \\
& {$[2]$} & {$[0]$} & {$[1]$} & {$[2]$} & {$[2]$} & {$[0.00]$} \\
Gross spread (\%) & 4.82 & 2.28 & 4.23 & 5.10 & -1.77 & 0.00 \\
& {$[5.00]$} & {$[1.70]$} & {$[4.20]$} & {$[5.15]$} & {$[-1.63]$} & {$[0.00]$} \\
Pre-offer return (\%) & 107.76 & 72.63 & 45.21 & 117.89 & -58.63 & 0.00 \\
& {$[57.47]$} & {$[26.21]$} & {$[20.75]$} & {$[65.66]$} & {$[-42.47]$} & {$[0.00]$} \\
Announcement effect & -1.72 & -1.49 & -2.55 & -1.66 & -0.20 & 0.29 \\
(\%) & {$[-1.53]$} & {$[-1.48]$} & {$[-1.99]$} & {$[-1.48]$} & {$[-0.26]$} & {$[0.18]$} \\
Discount (\%) & 2.75 & 3.93 & 2.43 & 2.66 & -0.54 & 0.02 \\
& {$[1.93]$} & {$[3.44]$} & {$[0.90]$} & {$[1.89]$} & {$[-0.37]$} & {$[0.08]$} \\
Underpricing (\%) & 3.11 & 1.09 & 2.10 & 3.43 & -1.85 & 0.00 \\
& {$[1.51]$} & {$[0.24]$} & {$[0.94]$} & {$[1.87]$} & {$[-1.43]$} & {$[0.00]$} \\
Number & 3,276 & 290 & 276 & 2,710 & - & - \\
\hline
\end{tabular}

